\title{
Elucidating the Cooperative Roles of Water and Lewis Acid-Base Pairs in Cascade C-C Coupling and Self-Deoxygenation Reactions
}

\author{
Houqian Li, Dezhou Guo, ${ }^{\dagger}$ Nisa Ulumuddin, ${ }^{\dagger}$ Nicholas R. Jaegers, Junming Sun, * Bo Peng, \\ Jean-Sabin McEwen, Jianzhi $\mathrm{Hu}$, and Yong Wang*
}

Cite This: JACS Au 2021, 1, 1471-1487

Read Online

\section{ACCESS |}

山ll Metrics \& More

Article Recommendations

Supporting Information

ABSTRACT: Water plays pivotal roles in tailoring reaction pathways in many important reactions, including cascade $\mathrm{C}-\mathrm{C}$ bond formation and oxygen elimination. Herein, a kinetic study combined with complementary analyses (DRIFTS, isotopic study, ${ }^{1} \mathrm{H}$ solid-state magic angle spinning nuclear magnetic resonance) and density functional theory (DFT) calculations are performed to elucidate the roles of water in cascade acetone-to-isobutene reactions on a $\mathrm{Zn}_{x} \mathrm{Zr}_{y} \mathrm{O}_{z}$ mixed metal oxide with balanced Lewis acid-base pairs. Our results reveal that the reaction follows the acetone-diacetone alcohol-isobutene pathway. Isobutene is produced through an intramolecular rearrangement of the eight-membered ring intermediate formed via the adsorption of diacetone alcohol on the Lewis acid-base pairs in the

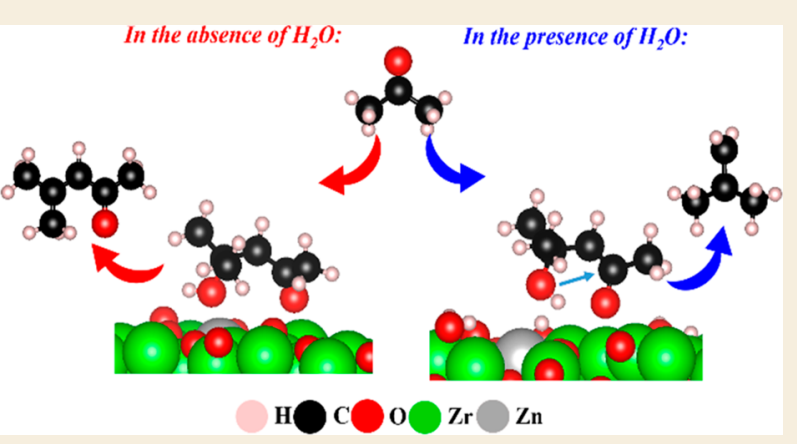
presence of cofed water. $\mathrm{OH}$ adspecies, formed by the dissociative adsorption of water on the catalyst surface, were found to distort diacetone alcohol's hydroxyl functional group toward its carbonyl functional group and facilitate the intramolecular rearrangement of diacetone alcohol to form isobutene. In the absence of water, diacetone alcohol binds strongly to the Lewis acid site, e.g., at a $\mathrm{Zr}^{4+}$ site, via its carbonyl functional group, leading to its dramatic structural distortion and further dehydration reaction to form mesityl oxide as well as subsequent polymerization reactions and the formation of coke. The present results provide insights into the cooperative roles of water and Lewis acid-base pairs in catalytic upgrading of biomass to fuels and chemicals.

KEYWORDS: water, deoxygenation, aldolization, Lewis acid-base, metal oxide

\section{INTRODUCTION}

$\mathrm{C}-\mathrm{C}$ coupling coupled with oxygen elimination is one of the most promising ways to produce valuable chemicals and fuels from biomass-derived oxygenates (e.g., alcohol, ketone, carboxylic acids), ${ }^{1-3}$ e.g., diacetone alcohol (DAA) and mesityl oxide (MSO) from acetone. Since McAllister et al. first reported on DAA and MSO conversion to isobutene, ${ }^{4}$ extensive studies have been conducted on the direct acetoneto-isobutene conversion (ATIB). ${ }^{4-11}$ This ATIB cascade reaction, including enolization, $\mathrm{C}-\mathrm{C}$ coupling (aldol-addition), dehydration, $\mathrm{C}-\mathrm{C}$ bond scission, and ketonization, may occur depending on the type of active sites (i.e., Brønsted acid sites $^{5,10,11}$ vs Lewis acid-base pairs ${ }^{8,12}$ ). Over zeolites with Brønsted acid sites, the cascade ATIB via aldol condensation of acetone followed by deoxygenation have been widely accepted. $^{10,11}$ Recent mechanistic insights reveal that the ATIB over Brønsted acid sites ${ }^{5,6,9,11}$ generally starts with the protonation of acetone followed by $\mathrm{C}-\mathrm{C}$ coupling to form acetone dimers (e.g., DAA, MSO, isomesityl oxide, etc.); the formed dimers then undergo facile $\beta$-scission to produce isobutene (Scheme 1). ${ }^{5,13}$ Other than the $\beta$-scission, there are also competing pathways, which results in the formation of large oligomers and rapid deactivation of the catalyst as well as cracking and isomerization of isobutene, especially at higher reaction temperatures (i.e., $>643 \mathrm{~K}$ ). ${ }^{6,9}$ In addition to this, zeolites are less hydrothermally stable because of the facile leaching of aluminum cations as compared with metal oxides.

Over Lewis acid-base pairs, although acetone aldolization has been well studied and understood, ${ }^{14-16}$ reports on ATIB (i.e., $\mathrm{C}-\mathrm{C}$ coupling followed by self-deoxygenation) are still scarce. ${ }^{7,8,12}$ A spectroscopic study by Zaki et al. showed that the formation of isobutene arises from $\mathrm{C}-\mathrm{C}$ bond cleavage of acetone oligomers, i.e., MSO. By comparing the IR spectra of acetone/MSO on $\mathrm{SiO}_{2}, \mathrm{Al}_{2} \mathrm{O}_{3}, \mathrm{SiO}_{2} / \mathrm{Al}_{2} \mathrm{O}_{3}, \mathrm{~K}-\mathrm{SiO}_{2} / \mathrm{Al}_{2} \mathrm{O}_{3}$, and $\mathrm{Py}-\mathrm{SiO}_{2} / \mathrm{Al}_{2} \mathrm{O}_{3}$, it was found that MSO coordinates to Lewis acid-base pairs and can be converted into surface acetate species and gas-phase isobutene at high temperatures (573$673 \mathrm{~K}),{ }^{17}$ due to the nucleophilic attack of basic $\mathrm{OH}$ groups in their proximity. ${ }^{18}$ We reported that $\mathrm{Zn}_{x} \mathrm{Zr}_{y} \mathrm{O}_{z}$ catalysts with

Received: May 18, 2021

Published: August 17, 2021 
Scheme 1. ATIB over Brønsted Acid Sites and Lewis AcidBase Pairs

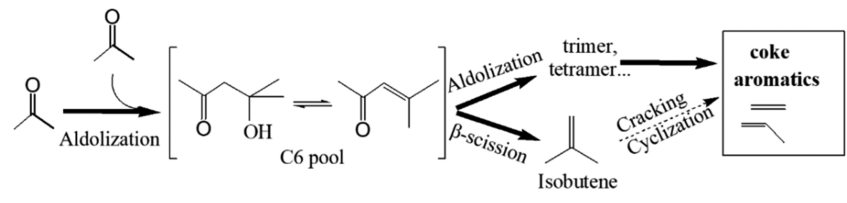

Bronsted acid sites

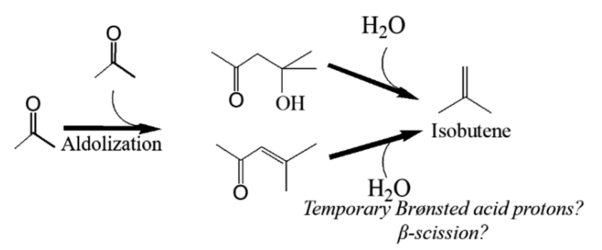

\section{Lewis acid-base pairs}

balanced Lewis acid-base pairs are active in the ATIB reaction in the presence of water. ${ }^{8}$ It was also found that the diacetone alcohol-to-isobutene step is a kinetically relevant one in cascade ATIB reactions. ${ }^{8}$ Rorrer et al. recently confirmed that isobutene is generated from DAA decomposition and the kinetic relevant step is the $\mathrm{C}-\mathrm{C}$ bond cleavage of DAA. ${ }^{12}$ They further postulated that surface hydroxyls and Brønsted acidic protons are generated by water dissociation, leading to the attack of protonated DAA by a hydroxyl species, but no evidence of Brønsted acidity was provided.

Although water has been found critical in many reactions including ATIB, its intrinsic roles are yet to be clarified. ${ }^{19-21}$ In the cascade ATIB reaction over zeolite catalysts, it was found that cofed water could mitigate the deactivation of the catalyst. ${ }^{8}$ It was proposed that cofed water could prevent the poisoning of bridging hydroxyls by coke components (e.g., large oligomers etc.) and thus suppressing the deactivation in acetone aldol condensation over zeolites. ${ }^{22,23}$ The content of water also affects the surface properties, which further influences the catalyst performance (e.g., stability, selectivity). ${ }^{3}$ For example, during the conversion of ethanol to $\mathrm{C}_{3}-\mathrm{C}_{4}$ olefins in a zeolite-based catalyst, an appropriate amount of cofed water improves the formation of light olefins and the catalyst stability, which was attributed to (a) weakened surface acidic sites and thus an attenuation of the side cracking reactions; (b) a mitigated oligomerization, which subsequently prevents coke formation. On the other hand, a high water content coupled with high reaction temperatures could lead to the deactivation of the catalyst due to the dealumination and the deconstruction of microporous structures. ${ }^{3}$ It was also speculated that the production of isobutene is favored in the presence of cofed water, because water prevents the dehydration of DAA as well as further aldolization, although reasons behind this phenomenon were not discussed. ${ }^{22}$ Recent studies conducted by Herrmann et al. confirmed that water could slow down the deactivation of aluminosilicate catalysts in the ATIB reaction. ${ }^{5}$ They also discovered two $\beta$-scission pathways, the anhydrous and $\mathrm{H}_{2} \mathrm{O}$-mediated pathways, to produce isobutene. In the absence of water, dehydrated dimers are the only direct precursor of isobutene (anhydrous $\beta$ scission). However, when water is cofed with acetone, both DAA and dehydrated dimers are direct precursors of isobutene and the $\beta$-scission of DAA is $\mathrm{H}_{2} \mathrm{O}$-mediated. ${ }^{5}$ So far, the critical role of water in the Lewis acid-base pairs (i.e.,
$\mathrm{Zn}_{x} \mathrm{Zr}_{y} \mathrm{O}_{z}$ ) catalyzed ATIB reaction remains elusive. In this contribution, we combine in situ DRIFTS-pyridine, in situ ${ }^{1} \mathrm{H}$ NMR, reaction kinetics, DRIFTS-MS, isotopic labeling, and density functional theory (DFT) to elucidate the cooperative roles of Lewis acid-base pairs and cofed water, as well as the detailed reaction mechanism in ATIB on $\mathrm{Zn}_{x} \mathrm{Zr}_{y} \mathrm{O}_{z}$ catalysts.

\section{EXPERIMENTAL METHODS}

\subsection{Catalyst and Materials}

$\mathrm{Zn}_{1} \mathrm{Zr}_{10} \mathrm{O}_{z}$ was synthesized with $\mathrm{Zn}\left(\mathrm{NO}_{3}\right)_{2} \cdot 6 \mathrm{H}_{2} \mathrm{O}$ (Sigma-Aldrich, reactant grade, $98 \%)$ and $\mathrm{Zr}(\mathrm{OH})_{4}(\mathrm{MEL}, \mathrm{XZO} 631 / 01)$ by the incipient wetness impregnation method. The details of synthesis and characterization could be found elsewhere. ${ }^{8,24}$ Acetone (J.T. Baker, $99.8 \%$ ), $\mathrm{H}_{2}{ }^{18} \mathrm{O}$ (Sigma-Aldrich, 97 atom $\%{ }^{18} \mathrm{O}$ ), pyridine (J.T. Baker, $100 \%$ ), diacetone alcohol (Sigma-Aldrich, 99\%), and phorone_A (2,6-dimethyl-2,5-heptadien-4-one, Oakwood Chemical, 99.93\%) were used as purchased.

\subsection{Catalyst Characterization}

2.2.1. Diffuse Reflectance Infrared Fourier Transform Spectroscopy Analysis of Adsorbed Pyridine (DRIFTS-Py) and Acetone (DRIFTS-acetone). Infrared spectra of pyridine on the dehydrated and the hydrated sample were obtained at a resolution of $4 \mathrm{~cm}^{-1}$ between 4000 and $600 \mathrm{~cm}^{-1}$ using a Bruker Tensor 27 FTIR spectrometer. Inert gas $(5 \% \mathrm{Ar} / \mathrm{He})$ was flowed through a 50 mL Pyrex bottle to introduce gas phase pyridine into the DRIFTS in situ cell. About $20 \mathrm{mg}$ of the catalyst was loaded and pretreated at 723 $\mathrm{K}$ for $30 \mathrm{~min}$ in inert gas $(5 \% \mathrm{Ar} / \mathrm{He})$ flow (50 SCCM). After pretreatment, the sample was cooled to $323 \mathrm{~K}$, followed by the collection of background spectrum and pyridine adsorption (ca. 2.5 $\mathrm{kPa}, 10 \mathrm{~min}$ ) to obtain the pyridine spectra of the sample without water treatment. For the pyridine spectra of the hydrated sample, after pretreatment, water was pulsed in (ca. $3.2 \times 10^{-8} \mathrm{~mol} \mathrm{H}_{2} \mathrm{O} /$ pulse, 3 pulses in total) at $523 \mathrm{~K}$ followed by $30 \mathrm{~min}$ of purging with the same inert gas to remove any physiosorbed water. The treated sample was then cooled to $323 \mathrm{~K}$ followed by the same procedure to obtain the pyridine spectra of the hydrated sample. Other details of the procedure can be found elsewhere. ${ }^{7,25}$

2.2.2. Diffuse Reflectance Infrared Fourier Transform Spectroscopy-Mass Spectroscopy (DRIFTS-MS) Analysis of the Acetone $\mathrm{H}_{2}^{18} \mathrm{O}$ Reaction on $\mathrm{Zn}_{1} \mathrm{Zr}_{10} \mathrm{O}_{z}$. The isotopic study with labeled ${ }^{18} \mathrm{O}$ in water was performed with a DRIFTS-MS set up.

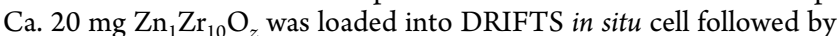
pretreatment at $723 \mathrm{~K}$ in $5 \% \mathrm{Ar} / \mathrm{He}(50 \mathrm{SCCM})$ for $30 \mathrm{~min}$. The gas phase water-acetone mixture $\left(\right.$ acetone $\mathrm{H}_{2} \mathrm{O}$ ) was introduced by slowly flowing (10 SCCM) 5\% Ar/He through the bubbler at room temperature. The system was then purged with $5 \% \mathrm{Ar} / \mathrm{He}$ for 40 min before introducing "Acetone $\mathrm{H}_{2}{ }^{18} \mathrm{O}$ " mixture. In the isotopic experiment ("Acetone $\mathrm{H}_{2}{ }^{18} \mathrm{O}$ "), partial pressure of gas phase acetone was $1.4 \mathrm{kPa}$ which was calculated by Henry's Law. We assume that the water pressure in the gas phase is the vapor pressure of water at $298 \mathrm{~K}$ $(3.2 \mathrm{kPa})$ because the effects of acetone to water evaporation were negligible, as the water to acetone molar ratio is large $(>50)$. To remove impurities (i.e., oxygen, $\mathrm{CO}_{2}$, etc.), the bubbler containing water-acetone solution ("Acetone $\mathrm{H}_{2} \mathrm{O}$ " or "Acetone $\mathrm{H}_{2}{ }^{18} \mathrm{O}$ ") was first purged in $5 \% \mathrm{Ar} / \mathrm{He}$ for $1 \mathrm{~h}$ before introducing to the cell. MS was used to monitor gas phase species for the entire process.

2.2.3. Solid-State Proton Nuclear Magnetic Resonance ( ${ }^{1} \mathrm{H}-$ SSNMR). ${ }^{1} \mathrm{H}$ solid-state magic angle spinning (MAS) nuclear magnetic resonance (NMR) experiments were conducted using a Varian Inova wide-bore $300 \mathrm{MHz}$ NMR spectrometer equipped with a $7.5 \mathrm{~mm}$ commercial ceramic probe. The samples were activated in a stream of $\mathrm{N}_{2}$ at $723 \mathrm{~K}$ and then transferred to a dry glovebox, where the samples were loaded into a custom-made $7.5 \mathrm{~mm}$ sealable rotor. ${ }^{26}$ Water was introduced to the sample via micro syringe prior to sealing the NMR rotor, this quantity was verified by mass change measured on an analytic balance. ${ }^{27}$ The amount of water (i.e., $1 \times 10^{-4} \mathrm{mmol}$ $\mathrm{H}_{2} \mathrm{O} / \mathrm{mg}_{\text {catal }}$ ) was controlled slightly less than total amount of surface Lewis acid sites on the same catalyst previously reported. ${ }^{8}$ Heating 
was conducted in situ via a heating stack externally calibrated with an ethylene glycol thermometer. ${ }^{28}$ The Larmor frequency was 299.969 $\mathrm{MHz}$ and a $\pi / 4$ pulse width of 3.5 with a $5 \mathrm{~s}$ recycle delay was employed to collect 128 repetitions.

\subsection{Catalytic Evaluation}

The measurements were performed in a home-built test unit which was described in our previous work. ${ }^{29}$ Specifically, a given amount of catalyst (i.e., $2.5-5 \mathrm{mg}$ ) diluted with $\mathrm{SiC}(500 \mathrm{mg}$ in total) was loaded into a microtubular fixed-bed reactor (i.d. Five $\mathrm{mm}$ ). The catalyst was heated to $723 \mathrm{~K}$ under $\mathrm{N}_{2}$ flow at 50 SCCM (hold at 723 $\mathrm{K}$ for $30 \mathrm{~min}$ ) to remove surface impurities prior to the evaluation of the catalyst. Steady-state isobutene formation rates were measured at $0.5-1.4 \mathrm{kPa}$ acetone and $4-17 \mathrm{kPa} \mathrm{H}_{2} \mathrm{O}$ at $723 \mathrm{~K}$. The acetonewater solution, with different ratios (i.e., $P_{\mathrm{H}_{2} \mathrm{O}} / P_{\text {Ace }}=6.5-17$ ), was evaporated and mixed with $\mathrm{N}_{2}$ in an evaporator, which was set at different temperatures $(303-383 \mathrm{~K})$ for a stable mixed flow. The flow rate of the mixed feed and the amount of catalyst loaded were adjusted to ensure the rate measurements under differential reactor conditions (conversion $<7 \%$ ). A customized Shimadzu GC-2014 gas chromatograph (GC) with HP-Plot Q column $(30 \mathrm{~m}, 0.53 \mathrm{~mm}, 40$ $\mu \mathrm{m}$ ), flame ionization detector (FID), and thermal conductivity detector (TCD) were used to analyze the products. The turnover rate for the isobutene formation was obtained by averaging at least 5 stable data points at steady states. To diminish the effect of deactivation on the kinetic measurements, the catalyst was regenerated every $180-$ 300 min time-on-stream with air (20 SCCM) to eliminate the coke (heavy oligomers) species. The regeneration was controlled less than 10 times. All the kinetic results were collected within 60-240 min time-on-stream on fresh or regenerated catalyst. A standard condition $\left(P_{\mathrm{H}_{2} \mathrm{O}}=10.7 \mathrm{kPa}, P_{\mathrm{Ace}}=0.7 \mathrm{kPa}, 723 \mathrm{~K}\right)$ was periodically used to measure the rate as a reference and the data which deviates from the reference was discarded. The same procedure was used for the conduction of DAA experiment except replacing acetone with DAA. After $90 \mathrm{~min}$ of steady state of the DAA-water experiment, the reactant was switched to pure DAA using GC to monitor the products.

Acetone conversion $(X)$, product selectivity $\left(S_{\mathrm{i}}\right)$, and turnover frequency of isobutene formation $\left(\mathrm{TOF}_{\mathrm{IB}}\right)$ were calculated as follows:

$$
\begin{aligned}
& \text { Conversion }(X)=\left(\mathrm{mol}_{\text {reactant-in }}-\mathrm{mol}_{\text {reactant-out }}\right) / \mathrm{mol}_{\text {reactant-in }} \\
& \text { Selectivity }{ }_{\text {species-I }}\left(S_{\mathrm{i}}\right)=\left(\mathrm{mol}_{\text {species-I }} \alpha_{\mathrm{i}}\right) /\left(\mathrm{mol}_{\text {converted reactant }} \beta\right) \\
& \text { Carbon balance }(\mathrm{CB}) \\
& \quad=(\text { sum of mol carbon in reactant } \\
& \quad \text { /sum of mol carbon in products }) 100 \%
\end{aligned}
$$

Turnover frequency of isobutene formation $\left(\mathrm{TOF}_{\mathrm{BB}}\right)$

$$
=\left(\text { flow rate } \text { reactant } X S_{\text {isobutene }} / 4\right) / L
$$

where $\alpha_{i}$ and $\beta$ refer to the carbon number in species- $i$ and reactant and $L$ refers to the total amount of catalytically relevant Lewis acidbase pairs (low/medium strength) calculated from $\mathrm{NH}_{3}$-TPD; the details can be found elsewhere. ${ }^{24}$

\subsection{Computational Details}

Density functional theory (DFT) simulations were conducted using the Vienna Ab initio Simulation Package (VASP) software ${ }^{30,31}$ to exhaustively simulate various adsorption configurations of DAA on model dehydrated and hydrated $\mathrm{Zn}_{x} \mathrm{Zr}_{y} \mathrm{O}_{z}$ surfaces. Electron smearing was performed with the Gaussian method with a smearing width of $0.2 \mathrm{eV}$, and the total energy was extrapolated to $0 \mathrm{~K}$. Geometric optimizations were considered converged when the total energy changed by less than $1 \times 10^{-6} \mathrm{eV}$ and interatomic forces were less than $0.02 \mathrm{eV} / \AA$ for the ground-state optimizations. The core electrons were described using the projector augmented wave (PAW) method that was released in $2017^{32,33}$ and the valence electrons were modeled using a plane-wave basis set that was expanded to a cutoff energy of $500 \mathrm{eV}$. The exchange-correlation potential was modeled with the
optB86b-vdW functional. ${ }^{34}$ The structure visualizations were performed with VESTA. ${ }^{35}$

Our $\mathrm{Zn}_{x} \mathrm{Zr}_{y} \mathrm{O}_{z}$ surface models were constructed based on $\mathrm{ZrO}_{2}$ crystalline. For zirconia, three polymorphic modifications have been reported experimentally at normal pressure. ${ }^{36}$ On the basis of the surface characterization of the $\mathrm{ZnZr}_{x} \mathrm{O}_{y}$ catalyst from a previous work, the most prevalent coordination environment of $\mathrm{Zn}^{2+}$ was the monoclinic $\mathrm{ZrO}_{2}\left(\mathrm{~m}-\mathrm{ZrO}_{2}\right)$ phase. ${ }^{24}$ Thus, the monoclinic $\mathrm{ZrO}_{2}$ (m$\mathrm{ZrO}_{2}$ ) was chosen as a starting point. The bulk phase lattice constants of the monoclinic phase were optimized using a Monkhorst-Pack (14 $\times 14 \times 14) k$-point mesh. ${ }^{37}$ The optimized $\mathrm{m}-\mathrm{ZrO}_{2}$ cell parameters are $a=5.14 \AA, b=5.24 \AA, c=5.31 \AA, \alpha=\gamma=90^{\circ}$, and $\beta=99.26^{\circ}$ from the DFT simulations, which agree very well with the X-ray experimental values of $a=5.17 \AA, b=5.23 \AA, c=5.34 \AA, \alpha=\gamma=90^{\circ}$, and $\beta=99.15^{\circ}$ at $293 \mathrm{~K}^{38}$ Thus, the DFT approach describes the crystal structure very well.

The (111) surface of $\mathrm{m}-\mathrm{ZrO}_{2}$ was modeled as it was identified as the most stable facet of $\mathrm{m}-\mathrm{ZrO}_{2} \cdot{ }^{39,40}$ The basic structure was modeled as a $p(2 \times 3) \mathrm{m}-\mathrm{ZrO}_{2}(\overline{1} 11)$ slab with three stoichiometric layers. The unit cell of the slab consists of $48 \mathrm{Zr}$ and $96 \mathrm{O}$ atoms and has a surface area of $13.54 \times 13.16 \AA^{2}$. In all geometry optimization calculations, the bottom two layers were fixed at their optimized bulk positions while the top layer was allowed to fully relax. A vacuum layer of $15 \AA$ and a dipole correction along the $z$-direction were incorporated for eliminating interactions between periodic images of the system. ${ }^{41} \mathrm{~A}$ Monkhorst-Pack $(2 \times 2 \times 1) k$-point mesh was used and all calculations were spin-polarized.

The clean $\mathrm{Zn}_{x} \mathrm{Zr}_{y} \mathrm{O}_{z}$ surface was modeled by replacing a $\mathrm{Zr}^{4+}$ to a $\mathrm{Zn}^{2+}$ at the terminal layer of the surface, forming a stoichiometric $\mathrm{Zn}_{1} \mathrm{Zr}_{11} \mathrm{O}_{12}$ catalyst. In addition, the $\mathrm{Zn}^{2+}$ cation was charge balanced by two protons which were placed at their most energetically favorable positions. Distinct substitution positions for $\mathrm{Zn}^{2+}$ were then scanned to obtain the final model shown in Figure 1A. The hydrated

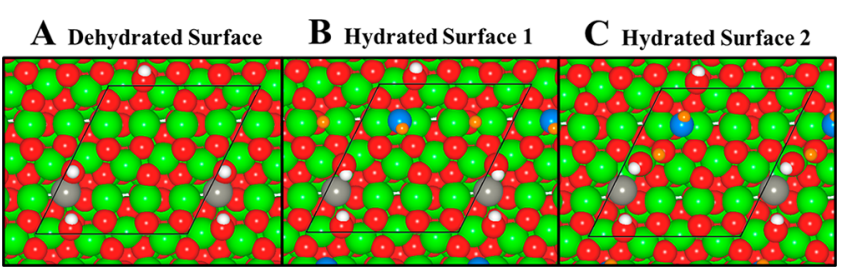

Figure 1. Top view of the (A) clean $\mathrm{Zn}_{1} \mathrm{Zr}_{11} \mathrm{O}_{12}$ surface; (B, C) hydrated $\mathrm{Zn}_{1} \mathrm{Zr}_{11} \mathrm{O}_{12}$ surface with one extra water molecule adsorbed. $\mathrm{The} \mathrm{Zr}, \mathrm{Zn}, \mathrm{O}$, and $\mathrm{H}$ atoms or ions are represented by green, gray, red, and white spheres, respectively. The adsorbed $\mathrm{O}$ and $\mathrm{H}$ atoms resulting from the dissociative adsorption of water are represented by blue and orange spheres, respectively, for clarity.

surface was modeled by adding one extra water molecule on the dehydrated surface. On the basis of the previous DFT results in the literature, water easily dissociates on the $\mathrm{m}-\mathrm{ZrO}_{2}(111)$ surface with a low activation barrier of $5.6 \mathrm{~kJ} / \mathrm{mol}^{8}$ Thus, we have systematically determined the most favorable coadsorption sites of $\mathrm{OH}$ and $\mathrm{H}$ on the model. Considering the complexity of the water cofed surface, two candidates were considered herein as shown in Figure 1B, C, labeled as Hydrated Surface Type 1 and Hydrated Surface Type 2, respectively, based on their underlying energetics. A comparison of all other dehydrated and hydrated surface models with respect to the most energetically favorable structures are displayed in Figures S1S4.

The adsorption sites of DAA were evaluated by calculating the adsorption energy of the DAA complex. This was calculated as

$$
E_{\text {ads }}=E_{\text {surface }+ \text { molecule }}-E_{\text {molecule }}-E_{\text {surface }}
$$

where $E_{\text {surface+molecule }}$ is the total energy of the DAA adsorbed on $\mathrm{Zn}_{1} \mathrm{Zr}_{11} \mathrm{O}_{12}, E_{\text {surface }}$ is the total energy of the clean $\mathrm{Zn}_{1} \mathrm{Zr}_{11} \mathrm{O}_{12}$ and $E_{\text {molecule }}$ is the isolated energy of DAA in gas phase. 
Another method for evaluating the strength of the interaction between the adsorbate and the surface is through the distortion energy, since the molecule will become distorted from its free gas geometry when it chemisorbs. The surface-adsorbate interaction will increase as its distortion energy increases. The energy that the adsorbate gains due to its geometric distortion from the interaction with the catalyst surface is quantified by evaluating:

$$
E_{\text {distortion }}=E_{\text {molecule }}^{\text {distorted geometry }}-E_{\text {molecule }}^{\text {free gas geometry }}
$$

where $E_{\text {molecule }}^{\text {dister geometry }}$ is the energy of distorted DAA in the gas phase, and $E_{\text {molecule }}^{\text {free gas geometry }}$ is the energy of the optimized DAA molecule in the gas phase.

The electronic interactions between molecule and the catalyst surface were also quantified through the differential charge density, which illustrates the movement of electrons in the system as the molecule adsorbs onto the surface. The differential charge density is calculated according to

$$
\Delta \rho(\vec{r})=\rho_{\text {total }}(\vec{r})-\rho_{\text {molecule }}(\vec{r})-\rho_{\text {surface }}(\vec{r})
$$

where $\rho_{\text {total }}(\vec{r}), \rho_{\text {molecule }}(\vec{r})$, and $\rho_{\text {surface }}(\vec{r})$ are the charge distribution for the whole system, the gas phase molecule and the catalyst surface, respectively. On the basis of the differential charge of electron density, we then integrated over the unit cell to give us the mean absolute charge transferred between the adsorbate and the surface $(Q)$ :

$$
Q=\frac{1}{2} \int \mathrm{d} r|\Delta \rho(\vec{r})|
$$

\section{RESULTS AND DISCUSSIONS}

\subsection{Distinct Role of Water in ATIB}

3.1.1. Effects of Water on Surface Acidity and Proton Formation. A detailed structural study of $\mathrm{Zn}_{x} \mathrm{Zr}_{y} \mathrm{O}_{z}$ has been previously reported. ${ }^{24}$ Herein, a comparison of fresh and spent (24 h time on stream, $P_{\mathrm{H}_{2} \mathrm{O}} / P_{\text {Ace }}=10.7 \mathrm{kPa} / 1 \mathrm{kPa}$, space velocity $\left.=0.03 \mathrm{~mol}_{\text {Ace }} /\left(\mathrm{g}_{\text {cat }} \mathrm{h}\right)\right) \mathrm{Zn}_{1} \mathrm{Zr}_{10} \mathrm{O}_{z}$ catalysts was carried out to examine the effect of water on the surface structure of the catalysts under the conditions studied, as shown in Figure S5. From DRIFTS analysis of surface hydroxyl groups (Figure $\mathrm{S} 5 \mathrm{~A}$ ), the stable surface monoclinic $\mathrm{ZrO}_{2}$ structure was confirmed. In addition, no $\mathrm{ZnO}$ phase was detected in the spent catalyst by XRD (Figure S5B) after $24 \mathrm{~h}$ of TOS, suggesting the framework $\mathrm{Zn}$ is stable under the reaction conditions (i.e., $<20 \mathrm{kPa}$ ). The surface of metal oxides consists of metal cations $\left(\mathrm{Zn}^{2+}\right.$ and $\mathrm{Zr}^{4+}$ for $\left.\mathrm{Zn}_{x} \mathrm{Zr}_{y} \mathrm{O}_{z}\right)$ and oxygen anions $\left(\mathrm{O}^{2-}\right.$ for $\left.\mathrm{Zn}_{x} \mathrm{Zr}_{y} \mathrm{O}_{z}\right)$ and can be terminated by $\mathrm{OH}$ groups as a result of charge balancing or water dissociative adsorption. ${ }^{42}$ Such surface hydroxyl groups may act as a proton donor (Brønsted acid site) based on the nature of $\mathrm{M}^{x+}-\mathrm{OH}$ bond, as has been demonstrated for $\mathrm{TiO}_{2}$ (P25) and $\mathrm{Al}_{2} \mathrm{O}_{3}$ as well as some other metal oxides. ${ }^{18,43}$ Over the $\mathrm{Zn}_{1} \mathrm{Zr}_{10} \mathrm{O}_{z}$ surface, our previous study (DRIFTS-pyridine) indicates that only Lewis acid-base pairs are present. ${ }^{8}$ The lack of isomerization/cracking products $\left(\mathrm{C}_{3}-\mathrm{C}_{5}\right.$ olefins $)$ suggests, indirectly, that Brønsted acid sites do not exist on a $\mathrm{Zn}_{1} \mathrm{Zr}_{10} \mathrm{O}_{z}$ surface under the reaction conditions studied (i.e., $723 \mathrm{~K}$, in the presence of cofeeding water) considering the unselective nature of Brønsted acidic protons for ATIB reactions. ${ }^{6,9,10,44}$

DRIFTS-Py experiments on $\mathrm{Zn}_{1} \mathrm{Zr}_{10} \mathrm{O}_{z}$ were conducted (Figure 2) to study the surface acidity in the absence and presence of water. It has been reported that water dissociation on $\mathrm{Zn}_{1} \mathrm{Zr}_{10} \mathrm{O}_{z}$ can readily occur at $423 \mathrm{~K}^{8}$ To investigate whether hydroxyl groups formed through the dissociation of water could play the role of a Brønsted acid site, the pretreated sample was rehydrated by pulsing water at $523 \mathrm{~K}$ before

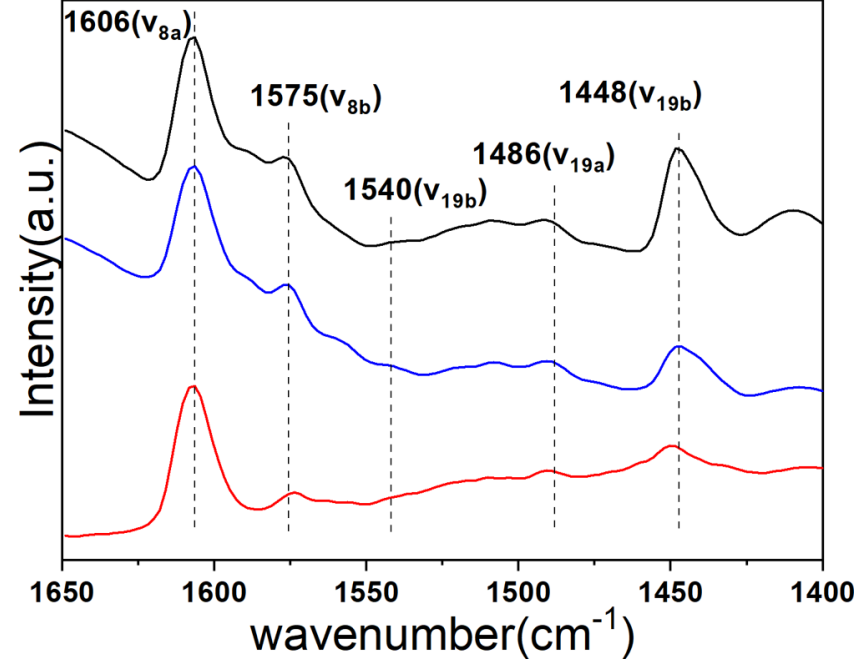

Figure 2. In situ DRIFTS-Py of pretreated (50 SCCM N 30 min at $723 \mathrm{~K}$ ) $\mathrm{Zn}_{1} \mathrm{Zr}_{10} \mathrm{O}_{z}$ (black) after water pulsing at $323 \mathrm{~K}$ (blue) and 523 $\mathrm{K}$ (red).

pyridine adsorption. Upon pyridine adsorption (Figure 2), $\nu(\mathrm{CCN})$ peaks at $1606,1575,1486$, and $1448 \mathrm{~cm}^{-1}$ appeared on both samples; characteristic of $8 \mathrm{a}, 8 \mathrm{~b}, 19 \mathrm{a}$, and $19 \mathrm{~b}$ vibration modes of hydrogen-bonded pyridine (HPy) or pyridine adsorbed on Lewis acid sites (LPy). ${ }^{42}$ Noteworthy, the $\nu_{19 \mathrm{~b}}$ of protonated pyridine $\left(1540 \mathrm{~cm}^{-1}\right)$ was not detected on the hydrated sample at both 323 and $523 \mathrm{~K}$ (blue and red curve), suggesting that surface $-\mathrm{OH}$ groups generated by water dissociation do not exhibit any Brønsted acidity. As compared to the dehydrated sample (black curve in Figure 2), a lower $\nu_{19 \mathrm{~b}}$ to $\nu_{8 \mathrm{a}}$ intensity ratio was observed in the hydrated sample while the band shape and position barely changed. The decreased intensity of the $\nu_{19 \mathrm{~b}}$ mode relative to the $\nu_{8 \mathrm{a}}$ mode $\left(I_{19 \mathrm{~b}} / I_{8 \mathrm{a}}\right)$ suggests that water treatment leads to an increased ratio of HPy-to-LPy. ${ }^{42}$ This increased ratio is due to the water adsorption and dissociation occupying a portion of the surface Lewis acid sites, which decreases the number of Lewis acid sites for LPy and increases surface hydroxyls for HPy.

From the DRIFTS-Py result, $\mathrm{Zn}_{1} \mathrm{Zr}_{10} \mathrm{O}_{z}$ shows only Lewis acidity even in the presence of dissociated water on the catalyst's surface; however, the nature of surface protons in hydroxyl groups generated from the dissociated water may be different on the Lewis acid-base pairs. SSNMR is a powerful method to characterize the acidity of solid catalysts ${ }^{45,46}$ and ${ }^{1} \mathrm{H}$-SSNMR measurements were performed to further explore the effects of water on the properties of surface acidity. Figure 3 depicts the spectra of the dehydrated and rehydrated $\mathrm{Zn}_{1} \mathrm{Zr}_{10} \mathrm{O}_{z}$ samples at 298 and $473 \mathrm{~K}$. The spectra of dehydrated samples at 298 and $473 \mathrm{~K}$ show two similar major peaks at $2.5 \mathrm{ppm}$ (full width at half-maximum, fwhm $=$ $841 \mathrm{~Hz}$; broad peak) and $1.8 \mathrm{ppm}(\mathrm{fwhm}=60 \mathrm{~Hz}$; sharp peak) which can be ascribed to surface bridged $\left(\mathrm{OH}_{\mathrm{B}}\right)$ and terminal hydroxyl groups $\left(\mathrm{OH}_{\mathrm{T}}\right)$, respectively, similar to other metal oxide species. ${ }^{47-49}$ Such $\mathrm{OH}_{\mathrm{B}}$ species have also been ascribed to $\mathrm{Zr}-\mathrm{OH}$ species that are in proximity to the Lewis acid $\mathrm{Zr}^{4+}$ site. ${ }^{50}$ In either case, ammonia adsorption does not lead to a protonated $\mathrm{NH}_{4}{ }^{+}$cation, demonstrating that $\mathrm{OH}_{\mathrm{B}}$ species are not acidic to an extent sufficient to catalyze this reaction. ${ }^{51}$ As compared to the $\mathrm{OH}_{\mathrm{B}}$ resonance, sharper $\mathrm{OH}_{\mathrm{T}}$ signals were observed that might be ascribed to a greater homogeneity of the local nuclear environment instigated by the enhanced 

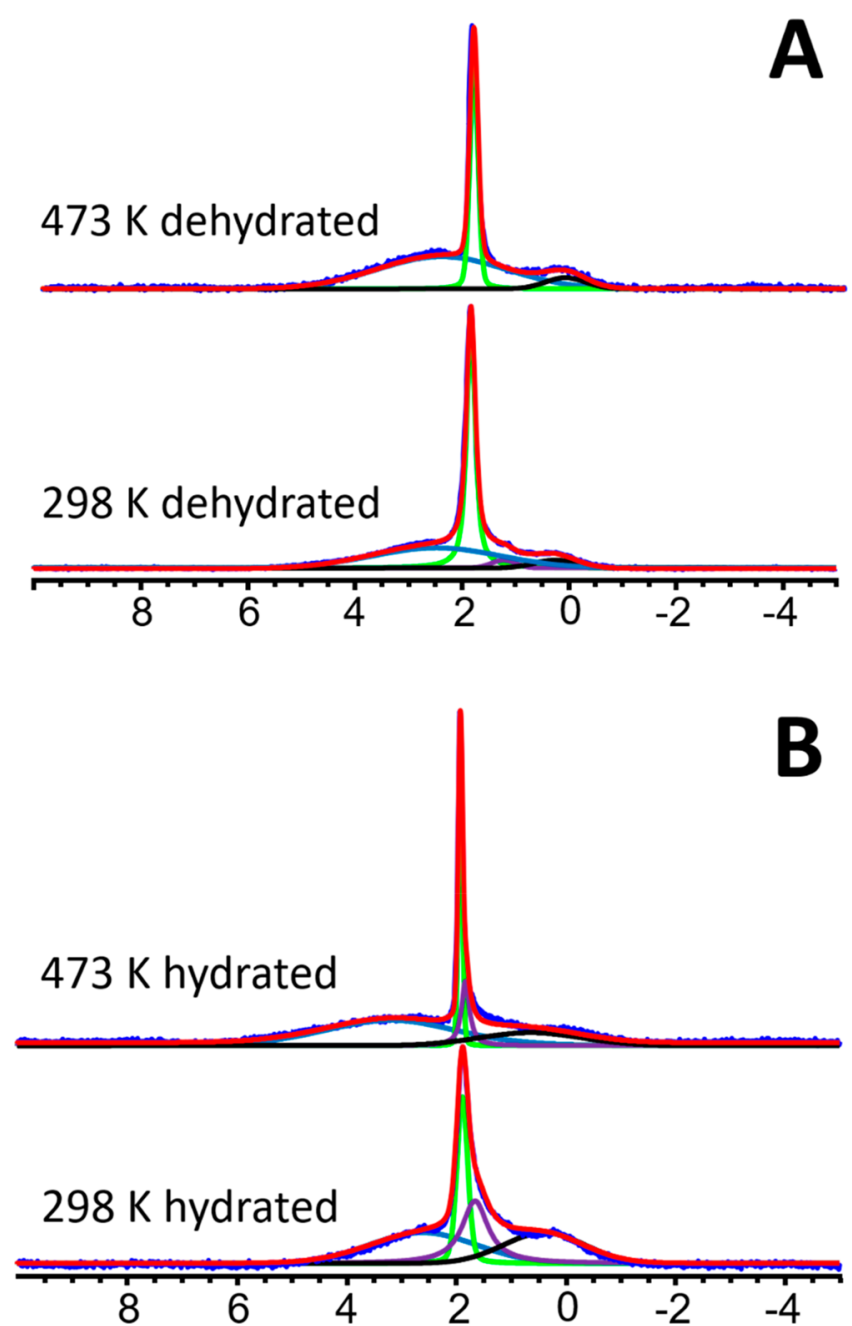

Figure 3. In situ ${ }^{1} \mathrm{H}$ NMR of (A) dehydrated and (B) hydrated $\mathrm{Zn}_{1} \mathrm{Zr}_{10} \mathrm{O}_{z}$ at 298 and $473 \mathrm{~K}$. Collected data are represented in dark blue, whereas the total model fit is displayed in red.

mobility of $\mathrm{OH}_{\mathrm{T}}$ at elevated temperatures because of their relatively free nature. Further, such species are likely related to the interaction of $\mathrm{ZnO}$ with $\mathrm{ZrO}_{2}$ at the surface of the catalyst, as $\mathrm{ZrO}_{2}$ does not exhibit such features. ${ }^{49}$ Other minor peaks at $<1.5 \mathrm{ppm}$ are likely due to the weak or nonacidic $\mathrm{OH}_{\mathrm{T}}$ on $\mathrm{Zn}_{1} \mathrm{Zr}_{10} \mathrm{O}_{z} \cdot{ }^{50}$ The absence of signals at $>4.5 \mathrm{ppm}$ suggests that Brønsted acidic hydroxyl groups are not present on these mixed metal oxides. ${ }^{49,50}$ Similar spectra were observed on both dehydrated and hydrated samples except for the appearance of a relatively broad resonance centered at $1.7 \mathrm{ppm}$ on the hydrated samples. In addition, $\mathrm{OH}_{\mathrm{B}}$ downfield shifting occurred after high temperature activation on the hydrated sample (Figure 3B, $473 \mathrm{~K}$ ). The new peak at 1.7 ppm likely results from the formation of protons possessing unique Lewis basic oxygen sites during the rehydration process. It should be noted that such a sharp feature does not exist on $\mathrm{ZrO}_{2}$ materials, ${ }^{49}$ suggesting that these terminal sites may arise due to the incorporation of $\mathrm{Zn}$. These protons are relatively weakly bonded, evidenced by the enhanced apparent nuclear symmetry and downfield shift of nearly $0.2 \mathrm{ppm}$ at elevated temperatures. At $473 \mathrm{~K}$, the decreased peak width of $\mathrm{OH}_{\mathrm{T}}$ at ca. 1.7-1.9 ppm concomitant with a downfield shift (2.6 ppm to $3.2 \mathrm{ppm}$ ) of $\mathrm{OH}_{\mathrm{B}}$ is discerned, implying a more uniform $\mathrm{OH}_{\mathrm{T}}$ local environment and potentially suggesting an elongated $\mathrm{O}-\mathrm{H}$ bond of $\mathrm{OH}_{\mathrm{B}}$ over a hydrated $\mathrm{Zn}_{1} \mathrm{Zr}_{10} \mathrm{O}_{z}$ catalyst after high temperature activation. Given this, they may be hydroxyls that were more easily removed during the dehydration process. This would be consistent with our DRIFTS observations in which a reduction of Lewis sites is accompanied with an increase in surface hydroxyls. The downfield shifting of the $\mathrm{OH}_{\mathrm{B}}$ peak might be also due to $\mathrm{H}$ exchanging between water and surface hydroxyl groups which matches the facile $\mathrm{H}-\mathrm{D}$ exchange previously reported over $\mathrm{Zn}_{x} \mathrm{Zr}_{y} \mathrm{O}_{z}{ }^{8}$ More importantly, the lack of peaks in the downfield range (i.e., $>4.5 \mathrm{ppm}$ ) further confirms that no Brønsted acid sites are generated on the hydrated sample, consistent with the DRIFTS-Py result.

Comparing both the dehydrated sample and hydrated sample, the water treatment introduces new surface protons that likely result from the presence of oxygen vacancies, which could dissociate $\mathrm{H}_{2} \mathrm{O}$ through the transfer of one proton to a nearby site (e.g., oxygen atom or hydroxyl groups). ${ }^{52}$ A more uniform local environment and an improved mobility were obtained at a high temperature (i.e., $473 \mathrm{~K}$ ) as evidenced by the decreased fwhm of $\mathrm{OH}_{\mathrm{T}}$ and downfield shifting of $\mathrm{OH}_{\mathrm{B}}$ (Figure 3B). Cofed water does not induce Brønsted acid sites, although surface hydroxyl groups (especially $\mathrm{OH}_{\mathrm{B}}$ ) with greater mobility on $\mathrm{Zn}_{1} \mathrm{Zr}_{10} \mathrm{O}_{z}$ are achieved. In contrast to the reported ATIB on Brønsted acid sites (proton donors), the unique nature of Lewis acid-base pairs (electron pair acceptors/donors) on the $\mathrm{Zn}_{1} \mathrm{Zr}_{10} \mathrm{O}_{z}$ leads to a different acetone reaction pathway, which will be further discussed in the following sections.

3.1.2. Effects of Water on the ATIB Reaction Pathway. Previously, it has been proposed that direct decomposition of DAA to isobutene is a rate limiting step in the ATIB reaction. ${ }^{8}$ Water is not required assuming that DAA could be directly decomposed to isobutene based on the stoichiometry of the equation (DAA $\rightarrow$ isobutene $+\mathrm{CH}_{3} \mathrm{COOH}$ ), and it is reasonable to infer that water is also not required in the acetone aldol addition as well as the subsequent ketonization.

To further explore the role of water in the DAA-to-isobutene reaction, we compared the reaction of key intermediate, i.e., DAA, on the $\mathrm{Zn}_{1} \mathrm{Zr}_{10} \mathrm{O}_{z}$ with and without cofeeding water. As shown in Figure 4, the reaction was very stable, with ca. $94.5 \%$

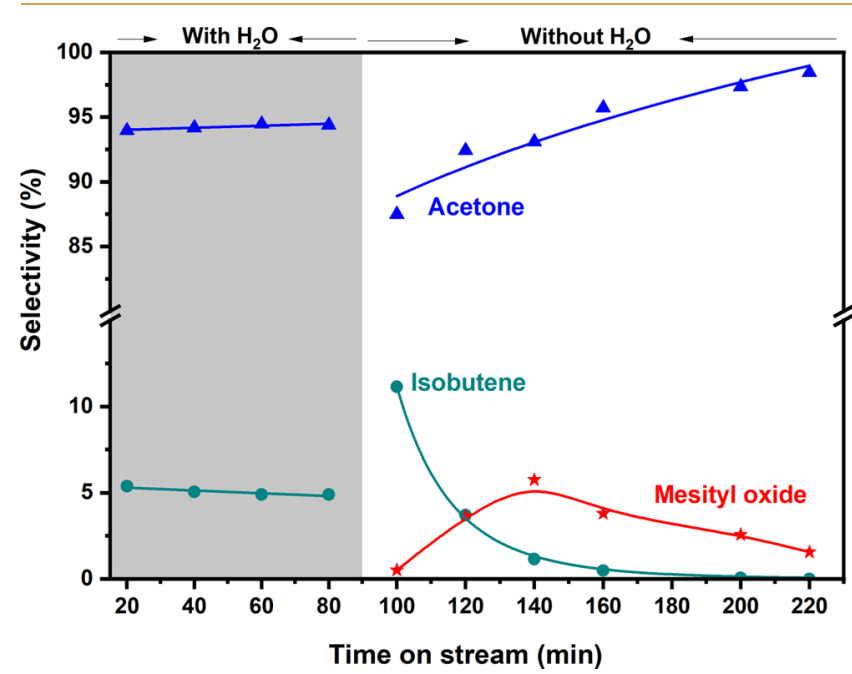

Figure 4. DAA reaction over $\mathrm{Zn}_{1} \mathrm{Zr}_{10} \mathrm{O}_{z}(5.5 \mathrm{mg})$ with/without cofeeding water, $T=723 \mathrm{~K}, W / F=0.0056 \mathrm{~g} \mathrm{~s} \mathrm{~mL}^{-1}, P_{\mathrm{DAA}}=0.5 \mathrm{kPa}$, $\mathrm{S} / \mathrm{C}=5$ for $\mathrm{H}_{2} \mathrm{O}$. 
Scheme 2. (A) Proposed Reaction Mechanism (acetone-phorone_A-isobutene) of the ATIB Cascade $\operatorname{Reaction}_{\text {over }} \mathrm{Zn}_{1} \mathrm{Zr}_{10} \mathrm{O}_{z}$; (B) Sequential Reaction Steps (acetone-phorone_A-isobutene) of the ATIB Cascade Reaction over $\mathrm{Zn}_{1} \mathrm{Zr}_{10} \mathrm{O}_{z}$

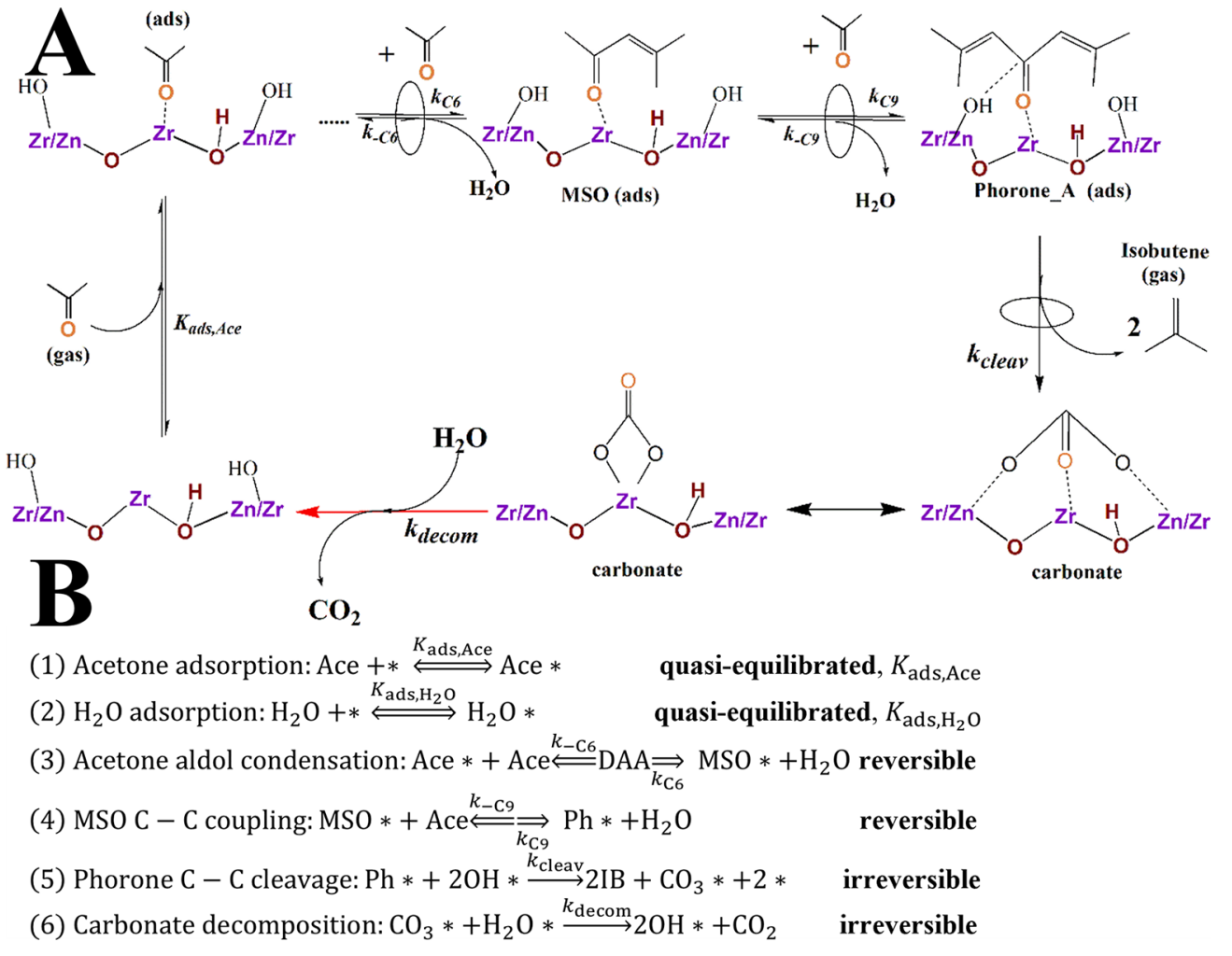

Scheme 3. Oxygen Resource of Different Acetone Surface Reactions over $\mathrm{Zn}_{1} \mathrm{Zr}_{10} \mathrm{O}_{z}{ }^{a}$

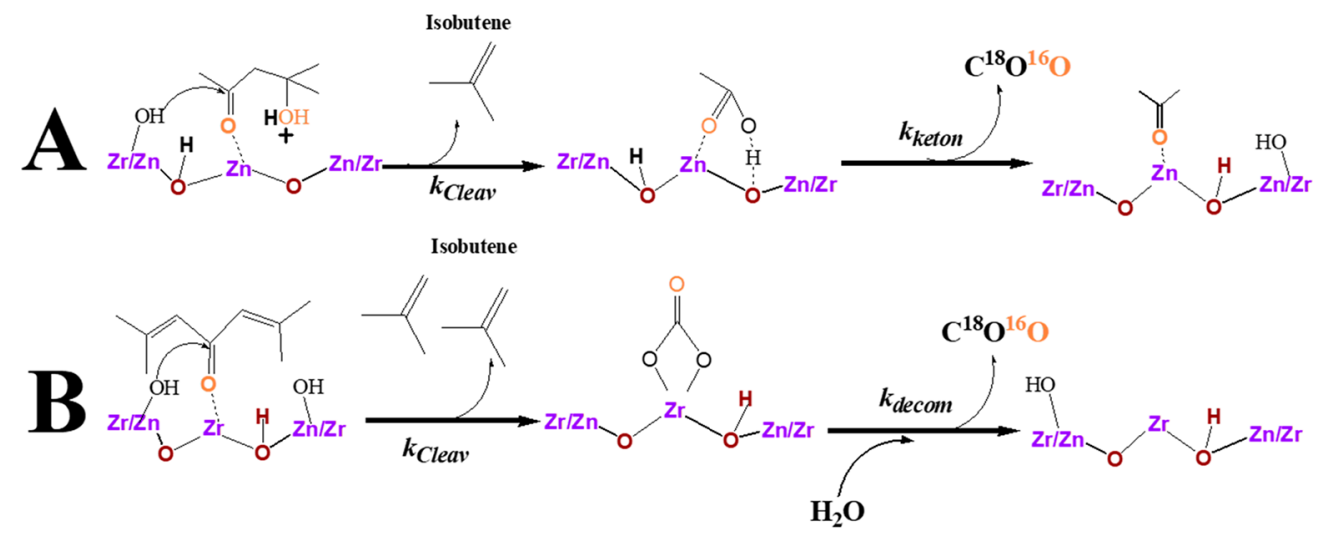

$C \mathrm{Y}_{\mathrm{O}}+5 \mathrm{H}_{2} \mathrm{O} \longrightarrow 8 \mathrm{H}_{2}+2 \mathrm{C}^{18} \mathrm{O}_{2}+\mathrm{C}^{18} \mathrm{O}^{16} \mathrm{O}$

\section{$D \underset{\mathrm{O}}{\mathrm{N}}+\mathrm{H}_{2} \mathrm{O} \longrightarrow 2 \mathrm{CH}_{4}+\mathrm{C}^{18} \mathbf{O}^{16} \mathrm{O}$}

${ }^{a} \mathrm{O}$ (orange) and $\mathrm{O}$ (dark red) represent ${ }^{16} \mathrm{O}$ (orange) and ${ }^{18} \mathrm{O}$ (black).

of acetone and $4.9 \%$ isobutene being formed, when water was cofed during the reaction. This result suggests that both the DAA-to-isobutene forward reaction and the DAA-to-acetone reaction occur, and the DAA-to-acetone reaction is much faster than the DAA-to-isobutene conversion. When water was not cofed in the feed, a doubled initial isobutene selectivity (i.e., $11.2 \%)$ was observed with the concurrent decrease of acetone selectivity $(87.5 \%)$. Note that ca. $0.5 \%$ of MSO was also detected. With time-on-stream, however, the selectivity to isobutene rapidly decreased and disappeared after $100 \mathrm{~min}$ of time-on-stream. Meanwhile, the selectivity to acetone increased monotonically and reached to ca. $100 \%$. The selectivity to MSO first increased then decreased and disappeared. These observations imply that, though it inhibited the forward DAA-to-isobutene reactivity, water helped maintaining active sites for the DAA-to-isobutene forward 
reaction likely via suppressed formation of MSO, a culprit that can readily poison/coke the acid sites. ${ }^{53}$ This comparison between the DAA reaction pathways with and without cofed water reveals that water plays an essential role in influencing the reaction pathway in the ATIB cascade reaction.

From our previous DRIFTS-MS experiments, ${ }^{7}$ the secondary MSO enolization followed by aldolization could only occur on balanced Lewis acid-base pairs (e.g., $\mathrm{Zn}_{1} \mathrm{Zr}_{10} \mathrm{O}_{z}$ ), leading to the formation of 2,6-dimethyl-2,5-heptadien-4-one (phorone_A) on the surface, another possible key intermediate to isobutene. ${ }^{7}$ Isobutene could be produced from phorone_A at low temperature (e.g., $373 \mathrm{~K}$ ). Otherwise, secondary $\mathrm{MSO}$ side reactions toward isophorone and other oligomers were observed on $\mathrm{ZrO}_{2}$ with weaker Lewis basicity which eventually blocked the active sites (i.e., Lewis acid-base pairs). Therefore, another possible reaction pathway of ATIB is proposed (Scheme 2): isobutene is produced from phorone_A, followed by the water-assisted decomposition of carbonate (surface residues after $\mathrm{C}-\mathrm{C}$ cleavage of phorone_A) releasing the active sites. Gorte and co-workers and Coenen et al. have demonstrated that water can enhance the decomposition of carbonate. ${ }^{54,55}$ In the DRIFTS-MS study of the acetone surface reaction, the carboxylate species dominate on the $\mathrm{Zn}_{1} \mathrm{Zr}_{10} \mathrm{O}_{z}$ surface in the absence of cofed water even at high temperatures. Our separate DRIFTS experiment also confirmed that the presence of water is beneficial to partially eliminate the strongly adsorbed surface carbonate on the $\mathrm{Zn}_{1} \mathrm{Zr}_{10} \mathrm{O}_{z}$ catalysts (Figure $\mathrm{S} 6$ ).

3.1.3. Possible Involvement of $\mathrm{H}_{2} \mathrm{O}$ in the ATIB Reaction. As mentioned above, two possible reaction pathways have been proposed where cofed water is involved in the reaction cycle (Scheme 3A, B). To further confirm that cofed water is indeed involved in reaction cycle, a DRIFTS-MS study of ${ }^{18} \mathrm{O}$-labeled water was utilized to examine the ATIB conversion.

Prior to the experiments, the possible oxygen distribution of the ${ }^{18} \mathrm{O}$ labeled water corresponding to each reaction pathway is proposed as shown in Scheme 3. When DAA is proposed as the direct precursor of isobutene, Brønsted acidic protons and surface hydroxyl groups (via water dissociation) promote the DAA decomposition to isobutene and acetic acid (as Rorrer et al. proposed, Scheme $3 \mathrm{~A}$ ), $\mathrm{CO}_{2}$ should be produced by a facile acetic acid ketonization, where $\mathrm{C}^{16} \mathrm{O}^{18} \mathrm{O}$ (MS signal: 46) is generated. ${ }^{12,56}$ If the reaction proceeds through the acetonephorone A-isobutene pathway (Scheme 3B), carbonate will be produce $\bar{d}$ via surface hydroxyl groups attacking the phorone_A. Coenen et al. reported that bidentate carbonate is stable at high temperatures (i.e., $>673 \mathrm{~K})^{54}$ and desorbed $\mathrm{CO}_{2}$ includes $\mathrm{C}=\mathrm{O}$ in carbonate based on the carbonate decomposition mechanism proposed by Burch. ${ }^{57}$ Thus, the decomposition of surface carbonate generated from phorone- $\mathrm{A}$ will also create $\mathrm{C}^{16} \mathrm{O}^{18} \mathrm{O}$. Moreover, $\mathrm{C}^{16} \mathrm{O}^{18} \mathrm{O}$ likely be produced via acetone decomposition pathway, whereas acetone steam reforming will lead to both $\mathrm{C}^{16} \mathrm{O}^{18} \mathrm{O}$ and $\mathrm{C}^{18} \mathrm{O}_{2}$, as exhibited in Scheme 3 .

Figure 5 depicts the evolving percentage of $\mathrm{C}^{16} \mathrm{O}_{2} / \mathrm{C}^{18} \mathrm{O}_{2} /$ $\mathrm{C}^{18} \mathrm{O}^{16} \mathrm{O}$ signal and DRIFTS spectra of surface hydroxyls in isotopic experiments. The reaction performance under similar isotopic experimental conditions is shown in Figure S7. No obvious deactivation was observed, and the selectivities barely changed. Because of the extremely low natural abundance of $\mathrm{H}_{2}{ }^{18} \mathrm{O}(<0.3 \%),{ }^{18} \mathrm{O}$-containing $\mathrm{CO}_{2}$ was not detected in the Acetone $\mathrm{H}_{2}{ }^{16} \mathrm{O}$ reaction (Figure $5 \mathrm{~A}$ ). Upon switching to
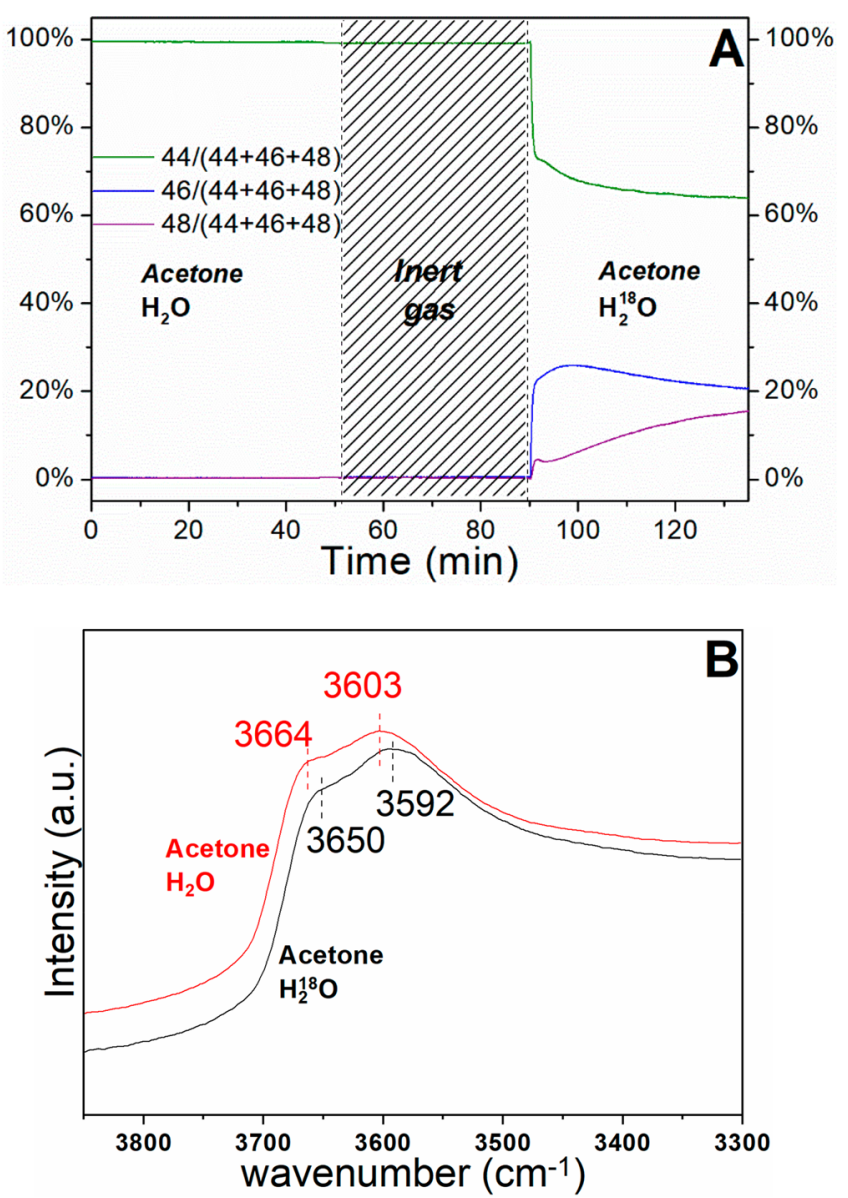

Figure 5. (A) Percentage of $44\left(\mathrm{CO}_{2}\right), 46\left(\mathrm{CO}^{18} \mathrm{O}\right)$, and $48\left(\mathrm{C}^{18} \mathrm{O}_{2}\right)$ signals; (B) DRIFTS of $\mathrm{Zn}_{1} \mathrm{Zr}_{10} \mathrm{O}_{z}$ surface hydroxyl groups $10 \mathrm{~min}$ purging after "Acetone $\mathrm{H}_{2} \mathrm{O}$ " or "Acetone $\mathrm{H}_{2}{ }^{18} \mathrm{O}$ " during isotopic study.

Acetone $\mathrm{H}_{2}{ }^{18} \mathrm{O}$, however, $\mathrm{C}^{16} \mathrm{O}_{2}$ was still dominant (64\%) with only $21 \% \mathrm{C}^{18} \mathrm{O}^{16} \mathrm{O}$ and $15 \% \mathrm{C}^{18} \mathrm{O}_{2}$ being observed in the $\mathrm{CO}_{2}$ (Figure 5A). From Scheme 3, $\mathrm{C}^{16} \mathrm{O}^{18} \mathrm{O}$ can be produced via water-involved ATIB pathways (Scheme 3A, B), ${ }^{7,12}$ acetone steam reforming (Scheme $3 \mathrm{C}$ ), and acetone decomposition (Scheme 3D), whereas $\mathrm{C}^{18} \mathrm{O}_{2}$ should only result from acetone steam reforming (Scheme $3 \mathrm{C}$ ). Based on the reaction stoichiometry (Scheme 3C, D), 7.5\% $\mathrm{C}^{18} \mathrm{O}^{16} \mathrm{O}$ should be obtained from the acetone steam reforming reaction (calculated by the detected $15 \% \mathrm{C}^{18} \mathrm{O}_{2}$ ), and $0.5 \% \mathrm{C}^{18} \mathrm{O}^{16} \mathrm{O}$ should be from acetone decomposition (calculated by the ca. $1 \%$ methane derived from the flow reactor under similar conditions). Upon subtraction of the $\mathrm{C}^{18} \mathrm{O}^{16} \mathrm{O}$ contribution from acetone steam reforming and acetone decomposition, ca. $13 \%$ of the obtained $\mathrm{C}^{18} \mathrm{O}^{16} \mathrm{O}$ was contributed by the "waterinvolved" ATIB reaction pathways (Scheme 3A, B). In addition, a red shift of peaks ascribed to hydroxyls was observed after $\mathrm{H}_{2}{ }^{16} \mathrm{O}$ was replaced with $\mathrm{H}_{2}{ }^{18} \mathrm{O}$ (Figure 5B) suggesting that water dissociates on the surface of catalyst. In Figure 4, the simultaneous disappearance of MSO and stable generation of isobutene likely be a result of the enhanced MSO-to-isobutene reaction in the presence of water. Note that, water must be involved in the reaction cycle if MSO is consumed to produce isobutene. However, the observation of minor $\mathrm{C}^{18} \mathrm{O}^{16} \mathrm{O}$ is contradictory to this assumption. The fact that a majority of $\mathrm{C}^{16} \mathrm{O}_{2}$ was detected in the Acetone $\mathrm{H}_{2}{ }^{18} \mathrm{O}$ 
Scheme 4. Oxygen Resource of the "No Water-Involved" Reaction Pathway in the (A) Presence and (B) Absence of Water over $\mathrm{Zn}_{1} \mathrm{Zr}_{10} \mathrm{O}_{z}$

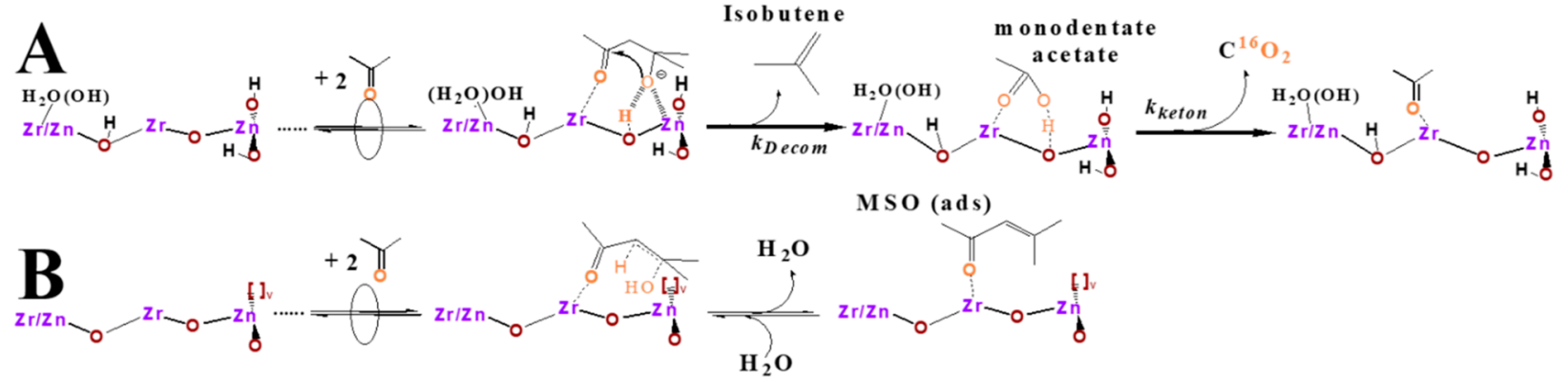

reaction points to an alternative pathway, which will be further discussed in the following sections.

As above-mentioned, based on the $\mathrm{CO}_{2}$ associated with the ATIB reaction $\left(64 \% \mathrm{C}^{16} \mathrm{O}_{2}+13 \% \mathrm{C}^{16} \mathrm{O}^{18} \mathrm{O}\right)$, one can conclude that the majority of ATIB reactions (i.e., $83 \%$, $64 \% /(64 \%+13 \%))$ do not involve water. Therefore, we propose and confirm in the next section another possible reaction pathway to form isobutene and surface acetic acid/ acetate via an intramolecular rearrangement of DAA (Scheme $4 \mathrm{~A})$. As $\mathrm{CO}_{2}$ is generated by the subsequent ketonization of acetic acid/acetate, this unique reaction pathway leads to the exclusive production of $\mathrm{C}^{16} \mathrm{O}_{2}$ in the steady-state "Acetone $\mathrm{H}_{2}{ }^{18} \mathrm{O}$ " reactions (Scheme $4 \mathrm{~A}$ ). On the other hand, concurrent MSO production and deactivation was observed in the absence of water while robust ATIB was achieved in the presence of water (Figure 4). Scheme 4 describes the possible pathways proposed for the two scenarios. Regardless of cofed water, acetone aldol addition is facile, leading to the formation of DAA. $^{25}$ Without cofed water, we postulate the density of surface oxygen vacancies or Lewis acid sites is high, and the formed surface DAA exposed to the vicinal acid sites or oxygen vacancies tends to dehydrate to form MSO, which eventually leads to surface polymerization/coking (Scheme 4B). ${ }^{58,59}$ With cofed water, because the majority of water is not involved in the catalytic reaction cycle as proposed in Scheme 4A, we hypothesize that the adsorbed water significantly reduces the density of surface oxygen vacancies or Lewis acid sites creating an environment around DAA which mediates its early transition state to form isobutene instead of MSO. On the basis of the NMR and DRIFTS results, water dissociation readily occurs, leading to the formation of newly generated hydroxyl groups and thus highly mobile protons on the catalyst surface, although the deprontonation energy of those protons are not low enough to show Brønsted acidity (section 3.1.1). The fact that DAA decomposition to isobutene was observed instead of DAA dehydration in the presence of cofed water further confirms the less-acidic nature of the protons. Rapid proton exchange between surface bridging hydroxyls and adsorbed molecules have been reported on both $\mathrm{Zn}_{x} \mathrm{Zr}_{y} \mathrm{O}_{z}{ }^{8}$ and $\mathrm{TiO}_{2} \cdot{ }^{60} \mathrm{We}$ postulate that the newly generated mobile protons in bridged hydroxyls over $\mathrm{Zn}_{1} \mathrm{Zr}_{10} \mathrm{O}_{z}$ facilitate the rearrangement of DAA, where $\mathrm{C}-\mathrm{O}$ bond cleaves and $\mathrm{O}-$ $\mathrm{C}(=\mathrm{O})$ bond forms simultaneously to form surface acetate and $\mathrm{C}-\mathrm{C}$ bond cleaves to release gas phase isobutene.

\subsection{Nature of Active Sites and Kinetic Analysis of ATIB} Reaction Over $\mathrm{Zn}_{1} \mathrm{Zr}_{10} \mathrm{O}$

In Section 3.1, we demonstrated that cofed water could not generate Brønsted acidity but creates more mobile protons via water dissociation on the Lewis acid sites of $\mathrm{Zn}_{1} \mathrm{Zr}_{10} \mathrm{O}_{z}$. Rather than being directly involved in the acetone-DAA-isobutene reaction cycle (Figure 4), cofed water prevents the DAA dehydration to MSO, a culprit causing the catalyst deactivation, and promotes a facile DAA decomposition to isobutene and surface acetic acid/acetate via a proposed intramolecular rearrangement pathway. To further elucidate the role of water, in this section, we combine the DRIFTS and kinetic analysis to explore the nature of binding sites and reaction mechanism for the ATIB reaction catalyzed by the balanced Lewis acid-base pairs on the $\mathrm{Zn}_{1} \mathrm{Zr}_{10} \mathrm{O}_{z}$. Although titration experiments are beneficial to elucidate the active sites on the surface, ${ }^{61,62}$ finding a suitable titrant that can survive under the current reaction conditions (i.e., high temperature, existence of water) is still challenging.

3.2.1. DRIFTS Study of Acetone Adsorption on $\mathrm{ZnO}$, $\mathrm{ZrO}_{2}$, and $\mathrm{Zn}_{1} \mathrm{Zr}_{10} \mathrm{O}_{z}$. A series of DRIFTS measurements were performed to explore the nature of binding sites for acetone adsorption and activation. Figure 6 displays the

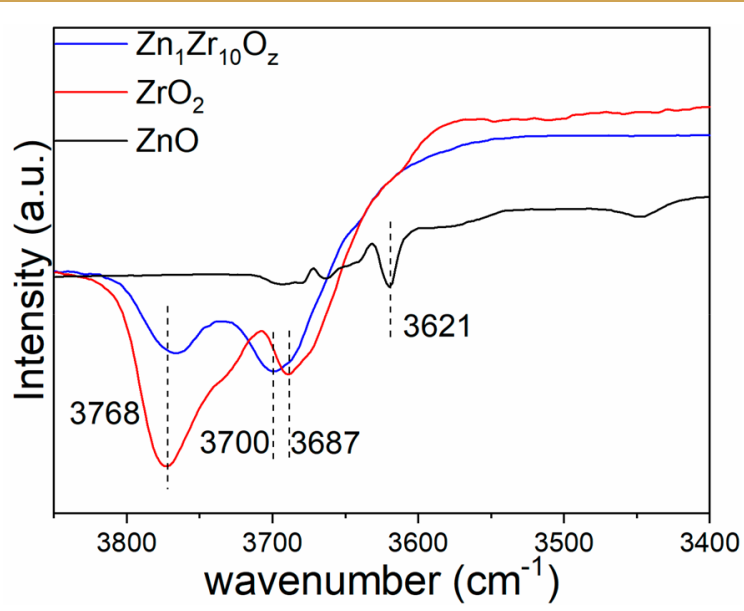

Figure 6. DRIFTS $\nu(\mathrm{OH})$ region of saturated acetone adsorption at $298 \mathrm{~K}$ on $\mathrm{ZnO}, \mathrm{ZrO}_{2}$, and $\mathrm{Zn}_{1} \mathrm{Zr}_{10} \mathrm{O}_{z}$.

acetone adsorption on $\mathrm{ZnO}, \mathrm{ZrO}_{2}$, and $\mathrm{Zn}_{1} \mathrm{Zr}_{10} \mathrm{O}_{z}$. Negative peaks in the $\nu(\mathrm{OH})$ region implies that surface $\mathrm{OH}$ groups were perturbed by acetone adsorption. As compared to the $\mathrm{Zn}_{1} \mathrm{Zr}_{10} \mathrm{O}_{z}$ spectrum, a much higher consumption of the terminal $\mathrm{OH}$ band at $3768 \mathrm{~cm}^{-1}$ was detected in the $\mathrm{ZrO}_{2}$ spectrum. Additionally, a blue shift of the bridged $\mathrm{OH}$ peak on $\mathrm{Zn}_{1} \mathrm{Zr}_{10} \mathrm{O}_{z}\left(3700 \mathrm{~cm}^{-1}\right)$ relative to $\mathrm{ZrO}_{2}\left(3687 \mathrm{~cm}^{-1}\right)$ was observed, likely due to perturbation of $\mathrm{Zn}^{2+}$ in the $\mathrm{ZrO}_{2}$ framework as reported in our previous work. ${ }^{24}$ A peak consumption at $3621 \mathrm{~cm}^{-1}$ was also discerned on $\mathrm{ZnO}$, 

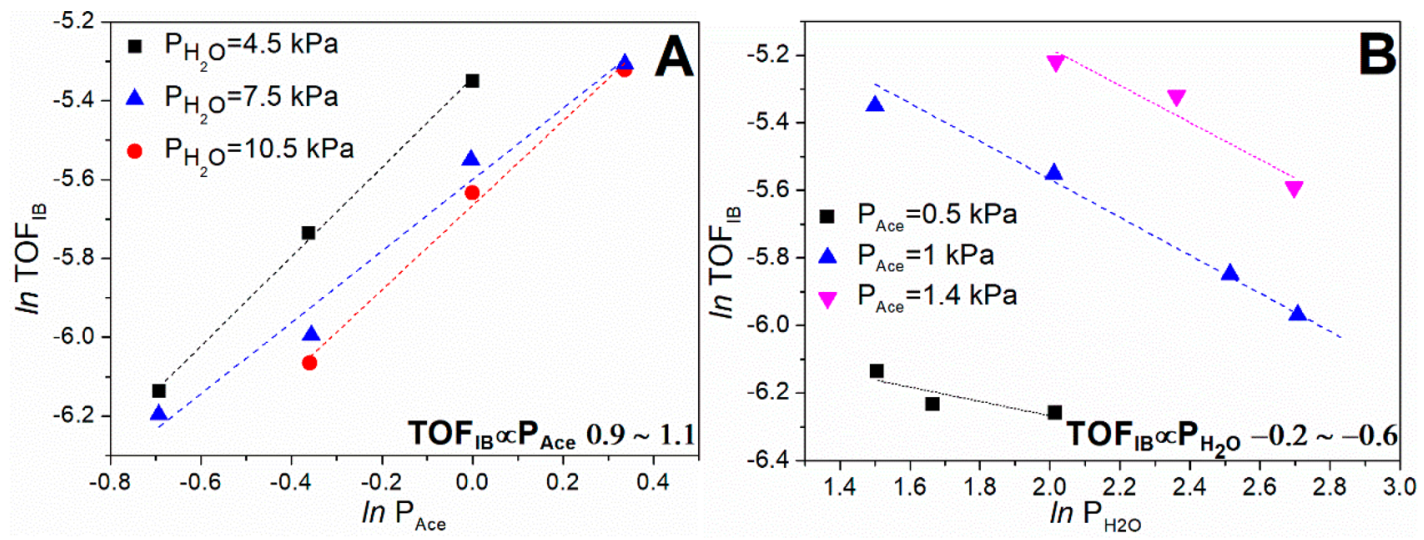

Figure 7. Steady-state $\mathrm{TOF}_{\mathrm{IB}}(723 \mathrm{~K})$ as a function of $(\mathrm{A})$ acetone and $(\mathrm{B})$ water partial pressure.

Scheme 5. (A) Proposed Reaction Mechanism (acetone-DAA-isobutene) of ATIB Cascade Reaction over $\mathrm{Zn}_{1} \mathrm{Zr}_{10} \mathrm{O}_{z}$; $(B)$ Sequential Reaction Steps (acetone-DAA-isobutene) of ATIB Cascade Reaction over $\mathrm{Zn}_{1} \mathrm{Zr}_{10} \mathrm{O}_{z}$

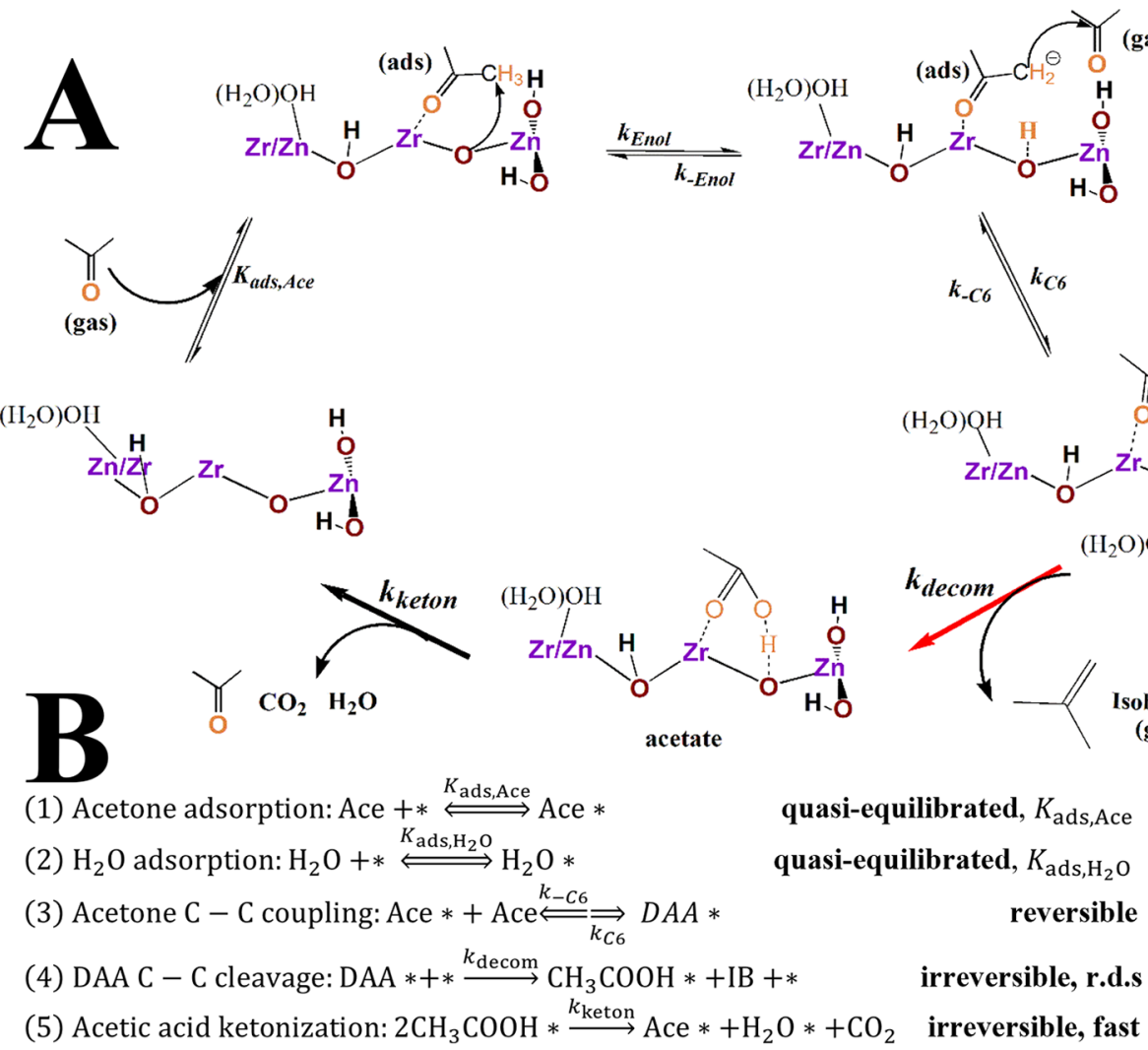

which can be attributed to $\mathrm{OH}$ groups related to oxygen vacancies on the $\mathrm{ZnO}$ oxide. ${ }^{63,64}$ This peak, however, was not observed on the $\mathrm{Zn}_{1} \mathrm{Zr}_{10} \mathrm{O}_{z}$ sample, further confirming the incorporation of $\mathrm{Zn}^{2+}$ in the $\mathrm{ZrO}_{2}$ framework. ${ }^{24}$

The structure of $\mathrm{Zn}_{1} \mathrm{Zr}_{10} \mathrm{O}_{z}$ mixed metal oxides has been studied, and it is found that incorporation of $\mathrm{Zn}^{2+}$ into the $\mathrm{ZrO}_{2}$ framework creates $\mathrm{Zn}-\mathrm{O}-\mathrm{Zr}$ moieties. ${ }^{24}$ Given the comparable surface areas of $\mathrm{ZrO}_{2}$ and $\mathrm{Zn}_{1} \mathrm{Zr}_{10} \mathrm{O}_{z}{ }^{8,24}$ a lower consumption of terminal hydroxyls on $\mathrm{Zn}_{1} \mathrm{Zr}_{10} \mathrm{O}_{z}$ relative to that on $\mathrm{ZrO}_{2}$ (Figure 6) indicates less adsorption of acetone on $\mathrm{Zr}$ cations associated with terminal hydroxyl groups over the former catalyst. Instead, our DRIFTS results and reaction data demonstrate an enhanced acetone enolization as well as $\mathrm{C}-\mathrm{C}$ coupling over $\mathrm{Zn}_{1} \mathrm{Zr}_{10} \mathrm{O}_{z}$, a strong indication that the ATIB reaction occurs on the $\mathrm{Zn}-\mathrm{O}-\mathrm{Zr}$ Lewis acid-base pair. ${ }^{8,25}$
Together with the dominant consumption of the blue-shifted peak at $3700 \mathrm{~cm}^{-1}$ on $\mathrm{Zn}_{1} \mathrm{Zr}_{10} \mathrm{O}_{z}$ (vs the dominant one at 3768 $\mathrm{cm}^{-1}$ on $\mathrm{ZrO}_{2}$ ), we propose that acetone predominantly adsorbs and is activated on the cationic sites (i.e., $\mathrm{Zr}^{\sigma+}$ ) in proximity to $\mathrm{Zn}^{2+}$ on $\mathrm{Zn}_{1} \mathrm{Zr}_{10} \mathrm{O}_{z}$, namely, the $\mathrm{Zr}^{\sigma+}-\mathrm{O}^{\alpha-}-\mathrm{Zn}$ Lewis acid-base pairs. The formation of the balanced $\mathrm{Zr}^{\sigma+}-$ $\mathrm{O}^{\alpha-}-\mathrm{Zn}$ site pairs not only enhance the aldol-addition of acetone to DAA, but also provides the required synergy for the subsequent DAA decomposition to isobutene on the $\mathrm{Zn}_{1} \mathrm{Zr}_{10} \mathrm{O}_{z}$ catalysts in the presence of cofed water. The details regarding the concerted reaction pathway will be further discussed in the following section.

3.2.2. Kinetic Study of Acetone-DAA-Isobutene Over $\mathbf{Z n}_{1} \mathbf{Z r}_{10} \mathbf{O}_{z}$. To further probe mechanism details, a kinetic study was conducted under differential conditions (conversion 
$<7 \%)$. The obtained acetone conversion and isobutene selectivities are plotted in Figure S8 as a function of inverse flow rate, in which a linear relationship between conversion and inverse flow rate confirms the differential reaction conditions. Additionally, the selectivity to isobutene remains the same at different residence times, suggesting that isobutene is the final product. Our previous work has shown high selectivity to isobutene (ca. $88.9 \%$ at $20 \%$ acetone conversion) and high stability (isobutene yield drops by $<3 \%$ after $200 \mathrm{~h}$ time-on-stream operation) on the $\mathrm{Zn}_{x} \mathrm{Zr}_{y} \mathrm{O}_{z}$ mixed metal oxides. ${ }^{8}$ Herein, at a significantly higher space velocity (30100 times of previous work), the stabilities of $\mathrm{Zn}_{1} \mathrm{Zr}_{10} \mathrm{O}_{z}$ were first examined to minimize the effect of deactivation on the rate measured. A slow deactivation took place at appropriate water pressures $\left(4 \mathrm{kPa}<P_{\mathrm{H}_{2} \mathrm{O}}<17 \mathrm{kPa}\right.$ ). Around $20 \%$ (from 3.2 to $2.6 \%)$ drop in acetone conversion was observed after ca. $37 \mathrm{~h}$ time-on-stream (Figure S9B); however, the deactivated catalyst can be fully regenerated in flowing air, suggesting that the reversible deactivation is mainly caused by coke that can be readily removed under oxidative conditions. Additionally, a comparison between a fresh catalyst and a 10-time-regenerated catalyst reveals a negligible effect on both conversion and selectivity (Figure S10). This result, consistent with the XRD and DRIFTS results of the spent catalysts (Figure S5), reveals that the structure of the catalyst remains stable under the reaction and regeneration conditions. Note that, at a water partial pressure $>20 \mathrm{kPa}$, the deactivated catalyst cannot be well regenerated, the reason of which is unclear, likely due to the water-induced formation of surface inactive phase. ${ }^{65}$

The kinetic effects of acetone and water partial pressure on the isobutene formation rate is depicted in Figure 7. Regardless of the water partial pressure, a first-order dependence on the acetone partial pressure (Figure 7A) was observed, suggesting that the reaction mechanism and surface dominant species barely changed under the conditions studied. A negative reaction order of water reveals the competitive adsorption between acetone (or acetone evolved surface species) and water on Lewis acid sites, similar as previously reported. ${ }^{66,67}$ Instead of completely blocking the Lewis acid sites and making those sites inaccessible to acetone, water should adsorb on part of Lewis acid sites at high temperature (i.e., $723 \mathrm{~K}$ ). The competitive adsorption of $\mathrm{H}_{2} \mathrm{O}$ and acetone was further evidenced by the more negative kinetic order of water at higher acetone partial pressures as shown in Figure $7 \mathrm{~B}$.

In section 3.1 and 3.2, a water mediated acetone-DAAisobutene dominant reaction pathway was uncovered in which water hindered MSO formation. The enhanced direct DAA decomposition to isobutene is likely to proceed via a proposed intramolecular rearrangement. Scheme 5 depicts the hypothesized reaction mechanism and corresponding elementary reaction steps during the ATIB reaction in the presence of water. Here, acetone adsorption/desorption and water adsorption/desorption are assumed as quasi-equilibrated steps. DAA is formed via a facile acetone aldol addition via an Eley-Rideal mechanism, which can readily occur even at room temperature. ${ }^{25}$ Given that the dehydration of DAA is significantly hindered by water, the MSO formation step will not be considered in this proposed kinetic model. Isobutene and surface acetate species are produced via the proposed intramolecular rearrangement of the eight-membered ring intermediate where $\mathrm{C}-\mathrm{C}$ bond cleavage and $\mathrm{C}-\mathrm{O}$ bond formation occur (Scheme 5A). Surface protons with greater mobility as evidenced by ${ }^{1} \mathrm{H}$ NMR may help facilitate the subsequent conversion of the DAA intermediate, producing isobutene and surface acetate via a concerted step. Our separate acetic acid experiments also revealed a much faster ketonization kinetics relative to that of the acetone to isobutene reaction (Figure S11). Additionally, the acetone$d_{6} / \mathrm{D}_{2} \mathrm{O}$ results suggest that $\alpha-\mathrm{H}$ abstraction and water dissociation are not kinetic relevant. ${ }^{8}$ Therefore, we propose the rate-determining-step (r.d.s.) of ATIB is the DAA decomposition. Assuming water and acetone are surface prevalent species, the isobutene formation rate can be described as eq 5 (detailed derivation is in Section S2 in the Supporting Information):

$$
\frac{r_{\mathrm{IB}}}{L}=\frac{k_{\mathrm{decom}} K_{\mathrm{C} 6} K_{\mathrm{ads}, \mathrm{Ace}} P_{\text {Ace }}^{2}}{\left(1+K_{\mathrm{ads}, \mathrm{Ace}} P_{\text {Ace }}+K_{\mathrm{ads}, \mathrm{H}_{2} \mathrm{O}} P_{\mathrm{H}_{2} \mathrm{O}}\right)^{2}}
$$

In eq $5, K_{\text {ads,Ace, }} K_{\mathrm{ads}, \mathrm{H}_{2} \mathrm{O}}$, and $K_{\mathrm{C} 6}$ represent the equilibrium constants of acetone adsorption, water adsorption, and acetone dimerization, respectively, whereas $k_{\text {decom }}$ is the rate constant for isobutene generation. The kinetic measurements at different water and acetone partial pressures is illustrated in Figure 8 . The $R$-square of 0.96 indicates that the proposed kinetic model reasonably describes the measured isobutene formaton rates.

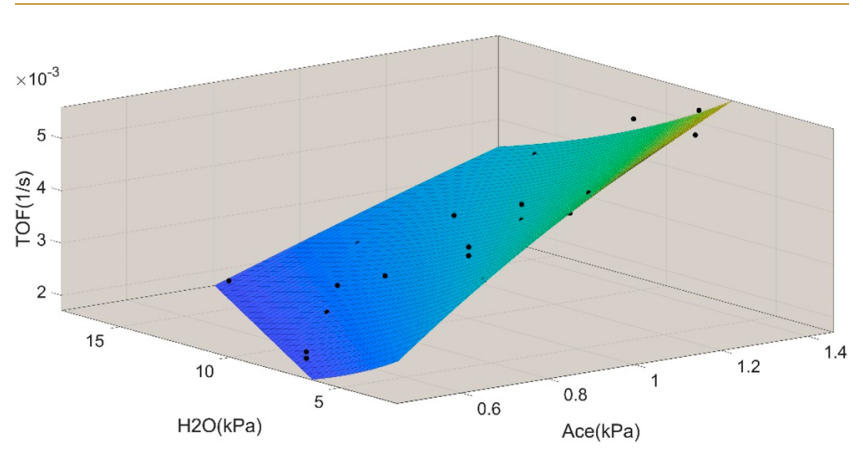

Figure 8. $\mathrm{TOF}_{\mathrm{IB}}$ as a function of $P_{\mathrm{H}_{2} \mathrm{O}}$ and $P_{\mathrm{Ace}}$ over $\mathrm{Zn}_{1} \mathrm{Zr}_{10} \mathrm{O}_{z}$ (acetone-DAA-isobutene, $723 \mathrm{~K}$, conversion $<7 \%$ ).

It is important to note that, despite the minor contribution of the "water-involved" pathway to the isobutene formation, this reaction pathway (Scheme 3A, B) includes both phoroneA secondary intermediate decomposition evidenced by our DRIFTS-MS ${ }^{7}$ and the surface hydroxyl-assisted DAA decomposition pathways proposed by Rorrer and co-workers. ${ }^{12}$ In principle, the measured rates can be fitted to the corresponding rate equation if the contribution of one pathway is negligible. However, if two "water-involved" reaction pathways are comparable and compromise each other, developing and fitting of two "water-involved" pathways could be very complicated and thus is not attempted in this study.

To further confirm that water promotes the DAA intramolecular rearrangement, $\mathrm{Zn}_{1} \mathrm{Zr}_{10} \mathrm{O}_{z}$ in the presence/absence of water was also evaluated, particularly focusing on how the water affects the apparent activation energy in the isobutene formation as shown in Figure 9. The calculated apparent activation barrier is $98.9 \mathrm{~kJ} \mathrm{~mol}^{-1}$ in the absence of water, which decreased to $88.2 \mathrm{~kJ} \mathrm{~mol}^{-1}$ at $P_{\mathrm{H}_{2} \mathrm{O}}=0.4 \mathrm{kPa}$. Because DAA is also the precursor of MSO (dehydration product), the fact that no MSO was observed even at $P_{\mathrm{H}_{2} \mathrm{O}}=0.4 \mathrm{kPa}$ 


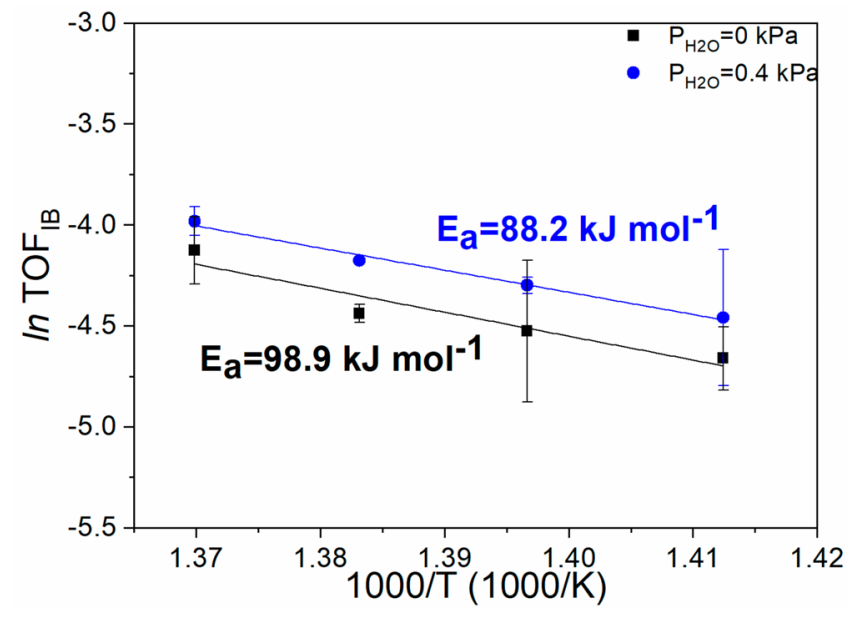

Figure 9. Temperature dependence of $\mathrm{TOF}_{\mathrm{IB}}$ extrapolated to $0 \mathrm{~min}$ time-on-stream with and without the presence of water $\left(P_{\mathrm{H}_{2} \mathrm{O}}=0.4\right.$ $\mathrm{kPa})$ at $708-730 \mathrm{~K}$. The vertical bars on each data point represent the repeated measurements and the mean value was used. The solid lines represent a linear fit to the experimental data.

indicates that the cofed water must have affected the dehydration activation barrier. As described in eq 6, assuming the surface coverage of adsorbed water can be ignored under both conditions (details in Figure S12, Figure S13), the formation rate ratio between isobutene and MSO exclusively reflects the differences in stability between two transition states of DAA decomposition and dehydration.

$$
\begin{aligned}
& \frac{r_{\text {DAA-isobutene }}}{r_{\text {DAA-MSO }}} \propto \frac{\frac{k_{\text {DAA-isobutene }}\left[\mathrm{DAA} *\left[{ }^{*}\right]\right.}{[*]+\left[\text { Ace }^{*}\right]}}{\frac{k_{\text {DAA-MSO }}\left[\mathrm { DAA } ^ { * } \left[\left[^{*}\right]\right.\right.}{[*]+\left[\text { Ace* }^{*}\right]}} \\
& =\frac{A_{\text {DAA-isobutene }}}{A_{\mathrm{DAA}-\mathrm{MSO}}} \\
& \exp \left(-\frac{E_{\mathrm{a}, \mathrm{DAA}-\text { isobutene }}-E_{\mathrm{a}, \mathrm{DAA}-\mathrm{MSO}}}{R T}\right)
\end{aligned}
$$

$k, A$, and $E_{\mathrm{a}}$ represent rate constant, pre-exponential factor, and apparent activation barrier of DAA-to-isobutene or DAA-toMSO. Note that the pre-exponential factor reflects the activation entropy. In the absence of water, the product distribution (Figure S13A) indicates that apparent activation barriers are comparable for the transition states of isobutene and MSO. However, in the presence of $0.4 \mathrm{kPa}$ water (Figure S13B), almost 10-fold difference between the normalized selectivity to isobutene and MSO suggests $r_{\text {DAA-isobutene }} \gg$ $r_{\text {DAA-MSO }}$. The decreased apparent activation barrier for DAAisobutene in the presence of water is likely a result of water altering the transition state. The slight decrease in $E_{\mathrm{a}, \mathrm{DAA} \text {-isobutene }}$ would result in the improved production of isobutene assuming water does not affect the MSO formation. However, the fact that a higher partial pressure of water significantly hinders the MSO formation suggests that water must have also increased the $E_{\mathrm{a}, \mathrm{DAA}-\mathrm{MSO}}$ or affect the activation entropy (i.e., $A_{\mathrm{DAA}-\text {-isobutene }} / A_{\mathrm{DAA}-\mathrm{MSO}}$ ratio), leading to the favorable DAA-isobutene pathway.

To conclude this section, acetone-DAA-isobutene was confirmed as the dominant reaction pathway where the r.d.s. is the decomposition of an eight-membered DAA-derived transition intermediate. The transition state is likely to be stabilized by two Lewis acid centers that complement each other through a unique local environment resulting from the co-adsorption of $\mathrm{H}_{2} \mathrm{O} / \mathrm{OH}$. We also demonstrated the multifaceted effects of water in the ATIB reaction in the following ways: (1) an appropriate amount of water is necessary to prevent the formation of MSO, a precursor to eventually form coke in the ATIB catalyzed by Lewis acidbase pairs; (2) surface protons with greater mobility on hydrated $\mathrm{Zn}_{1} \mathrm{Zr}_{10} \mathrm{O}_{z}$ create a favorable environment, which likely stabilize the transition state of an eight-membered ring intermediate enabling a robust ATIB reaction.

\subsection{Density Functional Theory Simulations}

3.3.1. DAA Adsorption on a $\mathrm{Zn}_{1} \mathrm{Zr}_{11} \mathrm{O}_{12}(\overline{1} 11)$ Surface. To study the adsorption of DAA on the dehydrated $\mathrm{Zn}_{1} \mathrm{Zr}_{11} \mathrm{O}_{12}$ (111) surface (Figure 1A), the plausible adsorption sites were systematically scanned with the DAA molecule both with horizontal and vertical configurations with its functional groups (FGs) pointing toward the surface. The corresponding site numbers and a top view of the corresponding configurations are shown in Figures S14, S17, and S18. To evaluate the strength of the interactions of DAA and the surfaces, the adsorption energy was calculated based on eq 1 . These energies of 24 distinct sites are plotted in Figure 10A. A strong average adsorption energy of $-2.91 \mathrm{eV}$

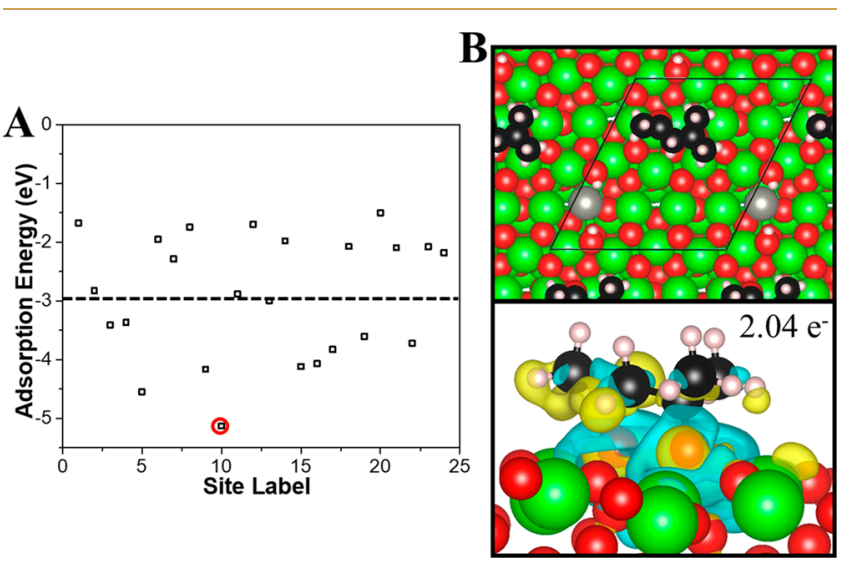

Figure 10. (A) Adsorption energies for the possible adsorption sites of DAA on a dehydrated $\mathrm{Zn}_{1} \mathrm{Z}_{11} \mathrm{O}_{12}$ (111) surface. (B) Top and side view for the adsorption of DAA at site 10 as marked by the red circle in panel $\mathrm{A}$. $\mathrm{Zr}, \mathrm{Zn}, \mathrm{C}, \mathrm{O}$, and $\mathrm{H}$ atoms or ions are represented by green, gray, black, red, and white spheres, respectively. Areas indicated in yellow represent those of electron gain while those in blue are those of electron loss upon the adsorption of the DAA molecule at an isosurface level of 0.002 electrons/Bohr ${ }^{3}$. Average value is marked by a black dashed line.

was found. To understand this, the adsorption configurations at Site 10 was taken as an example by performing a corresponding charge density difference analysis and calculating the mean absolute charge transfer according to eqs 3 and 4 . Both the hydroxyl and the carbonyl FGs were found to strongly interact with the surface. There is an electron gain that is predominantly localized within the oxygen FGs, leading to major electron losses from the surface $\mathrm{Zr}^{4+}$ cations. A minor charge transfer was observed from the molecule's carbon atoms to the adjacent hydrogen atoms near the FGs, inducing weaker dipole-dipole interactions with the surface. As a result, the strong attraction coming from an approximate charge transfer of 2.04 electrons (Figure 10B) leads to the strong adsorption 

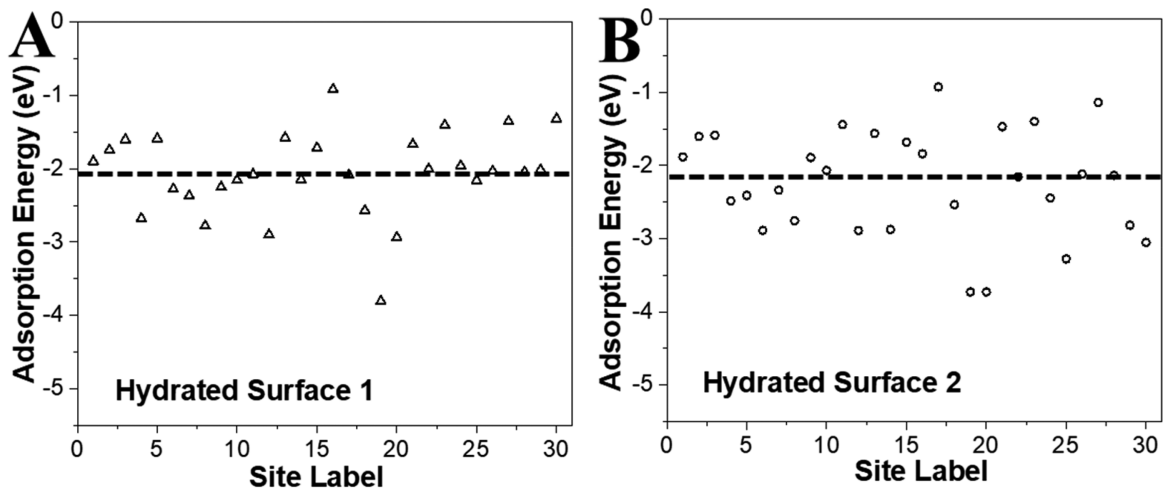

Figure 11. Adsorption energy of DAA molecule at hydrated surfaces (A) type 1 and (B) type 2, which are depicted in Figure 1 . Average values are marked by a black dashed line.
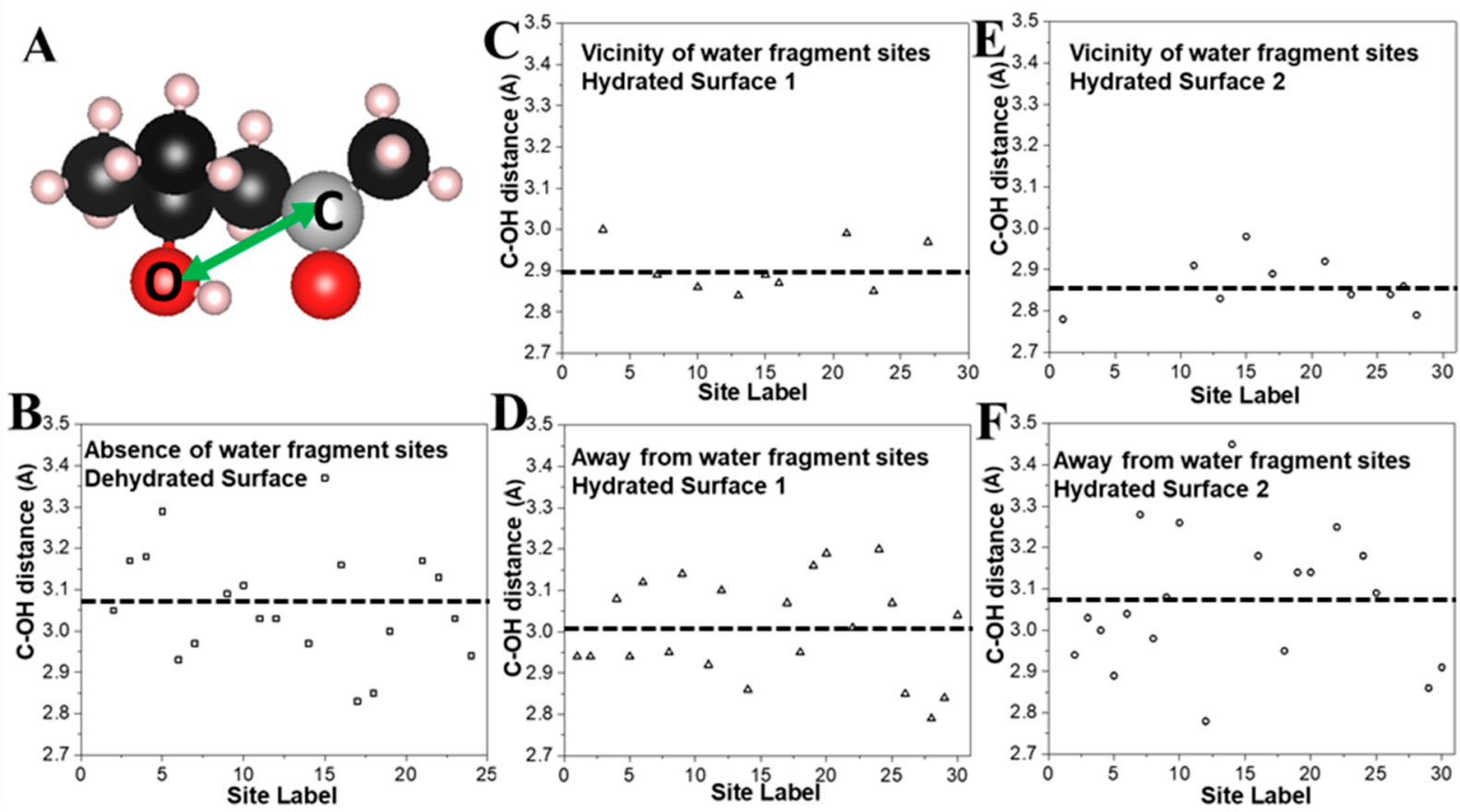

Figure 12. (A) DAA molecule. C, O, and $\mathrm{H}$ atoms are represented by black, red, and white spheres, respectively. Carbon atom of carbonyl FG is represented by gray sphere for clarity. Green arrow represents the distance between the oxygen atom of the hydroxyl function group and the carbon atom of the carbonyl FG. Illustrated carbon-oxygen distance was calculated either (B) in the absence of water fragments or (D, F) when the DAA is away from the water fragments. (C, E) DAA molecule is adsorbed in the vicinity of the water fragments for the two hydrated surface types as illustrated in Figure 1. Corresponding configurations are shown in Figures S14-S23. Average values are marked by a black dashed line.

energy of $-5.13 \mathrm{eV}$. Thus, the DAA molecule most favorably interacts with the $\mathrm{Zn}_{x} \mathrm{Z}_{y} \mathrm{O}_{z}$ surface through its two FGs because the FGs facilitate direct charge transfer to the surface. In addition, for comparison, the corresponding adsorption energies of DAA when its FGs point away from the surface were also determined, as shown in Figures S15, S16, and S19. Little charge transfer leads to the weak dipole-dipole interactions between $\mathrm{C}, \mathrm{H}$ and the surface ions, indicating that the DAA molecule is unlikely to adsorb in this configuration on a $\mathrm{Zn}_{x} \mathrm{Z}_{y} \mathrm{O}_{z}$ surface.

3.3.2. Role of Water. To understand the influence of water on the adsorption of DAA, a water molecule was adsorbed on the dehydrated $\mathrm{Zn}_{1} \mathrm{Zr}_{11} \mathrm{O}_{12}$ surface. The water molecule was assumed to decompose and form two hydroxyl groups. The hydrated surface models previously shown in Figure $1 \mathrm{~B}$ (Hydrated Surface Type 1) and Figure 1C (Hydrated Surface Type 2) were used to model their interaction with the adsorption of DAA. The adsorption energies at 30 distinct possible adsorption sites on these two model surfaces were systematically compared. The corresponding site numbers and the top view of these configurations are shown in Figures S14 and S20-S23. The calculated average adsorption energies of DAA are -2.07 and $-2.20 \mathrm{eV}$ on the Hydrated Surface Type 1 (Figure 11A) and Type 2 (Figure 11B), respectively, which are both weaker than those on the dehydrated surface, where DAA's average adsorption energy is $-2.91 \mathrm{eV}$. Therefore, water likely plays an important role toward affecting the adsorption strength of DAA.

Our experimental results indicate that cofed water enhances the production of isobutene and hindering the formation of MSO and its polymerization/coking reactions. Also, it is hypothesized that isobutene is produced by facilitating the attack of the DAA's hydroxyl toward the carbon atom of the carbonyl FG (illustrated in Figure 12A). The bond distance 
between the $\mathrm{C}$ of the carbonyl FG and the $\mathrm{O}$ of the hydroxyl FG was calculated to understand the role of water toward distorting the DAA adsorbate and facilitating the formation of isobutene. The average $\mathrm{C}-\mathrm{OH}$ distances are labeled in Figure 12 were bond lengths larger than $3.0 \AA$ occur when the DAA molecule adsorbs on sites that are outside the vicinity of adsorbed water fragments (3.01 $\AA$ on the Hydrated Surface Type 1 in Figure 12D; $3.07 \AA$ on the Hydrated Surface Type 2 in Figure 12F; and $3.07 \AA$ on the dehydrated surface in Figure $12 B)$. However, this average decreases to $\sim 2.88 \AA$ within the vicinity of the water fragments $(2.90 \AA$ on the Hydrated Surface Type 1 in Figure 12C; $2.86 \AA$ on the Hydrated Surface Type 2 in Figure 12E). Thus, the adsorbed water fragments likely tend to repel the FGs from the surface, bend the hydroxyl FG toward the carbonyl FG, which may facilitate DAA's further intramolecular arrangement to form isobutene.

To explain how the adsorbed water fragments affect the adsorption strength and deformation severity of DAA on the $\mathrm{Zn}_{1} \mathrm{Z}_{11} \mathrm{O}_{12}$ surface, we compared several related adsorption sites of the DAA on Hydrated Surface 1 and Hydrated Surface 2 to the dehydrated surface. Figures $13 \mathrm{~A}-\mathrm{D}$ show four sites

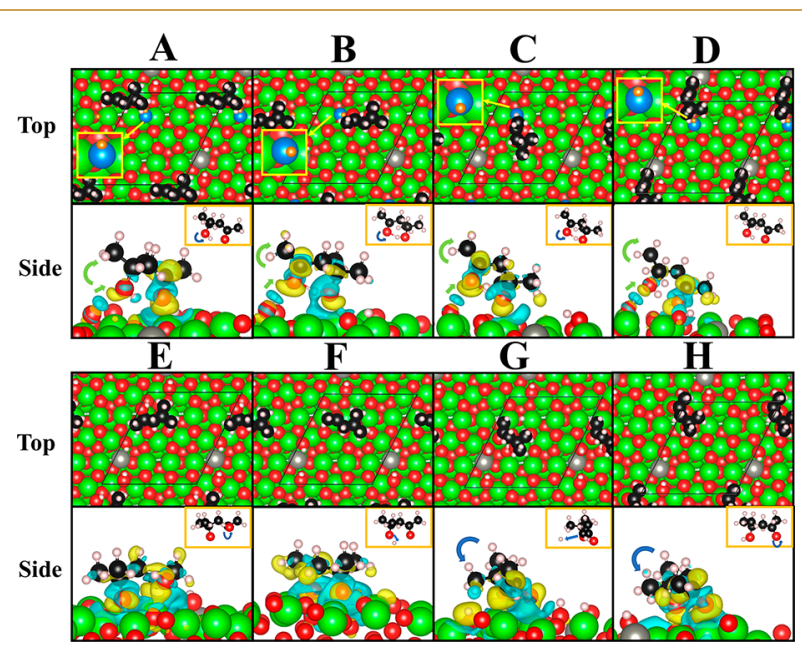

Figure 13. Top and side views of DAA (A-D) at sites within the vicinity of an adsorbed $\mathrm{OH}$ group on a hydrated surface type 1 and $(\mathrm{E}-\mathrm{H})$ at the corresponding sites on the dehydrated Surface. $\mathrm{Zr}, \mathrm{Zn}$, $\mathrm{C}, \mathrm{O}$, and $\mathrm{H}$ atoms or ions are represented by green, gray, black, red, and white spheres, respectively. Surface-adsorbed $\mathrm{O}$ and $\mathrm{H}$ atoms are represented by blue and orange spheres in the top views, respectively, for better illustration. Partial charge densities are presented by yellow isosurfaces for electron gains and by blue isosurfaces for electron losses with an isosurface value of 0.002 electrons/Bohr ${ }^{3}$.

where DAA adsorbs near the surface water $\mathrm{OH}$ fragments on Hydrated Surface 1 ("within the vicinity of surface $\mathrm{OH}^{\prime}$ ), whereas Figure 13E-H show four corresponding sites where DAA adsorbs on dehydrated Surface ("outside the vicinity of surface $\mathrm{OH}^{\prime}$ ). The detailed adsorption energy, distortion energy (based on eq 2), number of transferred electrons, and the $\mathrm{C}-\mathrm{OH}$ bond distances as illustrated in Figure 13 and are tabulated in Table 1 whose average values are shown in Figure 14.

Interestingly, the average adsorption energy when DAA adsorbs within the vicinity of a surface $\mathrm{OH}$ is $-1.48 \pm 0.06 \mathrm{eV}$, which is substantially weaker than when it is outside the vicinity of surface $\mathrm{OH}$, with a mean adsorption energy of $-3.81 \pm 0.63 \mathrm{eV}$. Such energy differences are clearly reflected in the differential charge analysis shown in Figure 13. As shown
Table 1. Adsorption Energy, Distortion Energy, Number of Transferred Electrons, and Carbonyl-Bonded CarbonHydroxyl Distance for Systems in Figure 13

\begin{tabular}{lcccc}
\multicolumn{1}{c}{ site } & $\mathrm{A}$ & $\mathrm{B}$ & $\mathrm{C}$ & $\mathrm{D}$ \\
\hline adsorption energy $(\mathrm{eV})$ & -1.60 & -1.58 & -1.40 & -1.35 \\
distortion energy $(\mathrm{eV})$ & 0.34 & 0.36 & 0.36 & 0.40 \\
transferred electron no. & 1.43 & 1.25 & 0.91 & 1.34 \\
$\mathrm{C}-\mathrm{O}$ distance $(\AA)$ & 3.00 & 2.84 & 2.85 & 2.97 \\
site & $\mathrm{E}$ & $\mathrm{F}$ & $\mathrm{G}$ & $\mathrm{H}$ \\
adsorption energy $(\mathrm{eV})$ & -4.17 & -5.13 & -3.83 & -2.10 \\
distortion energy $(\mathrm{eV})$ & 4.10 & 5.81 & 4.90 & 0.80 \\
transferred electron no. & 1.61 & 2.04 & 1.85 & 1.46 \\
C-O distance $(\AA)$ & 3.09 & 3.11 & 2.83 & 3.17
\end{tabular}

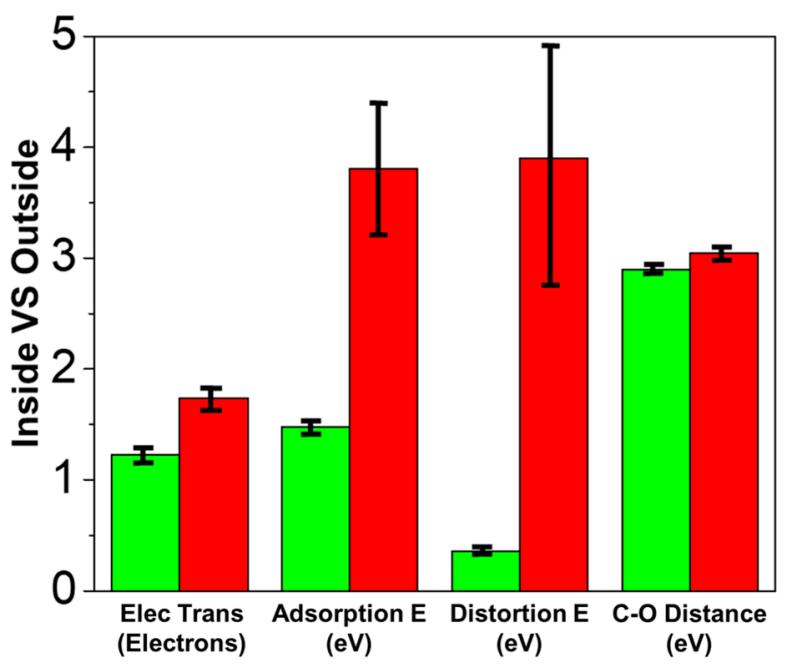

Figure 14. Comparison of average number of transferred electrons, adsorption energy, distortion energy, and carbonyl-bonded carbonhydroxyl distance for DAA at sites within and outside the vicinity of an adsorbed $\mathrm{OH}$ group for the configurations shown in Figure 13.

in the side view of Figure $13 \mathrm{E}-\mathrm{H}$, when DAA is far from a surface $\mathrm{OH}$, both FGs strongly bind with the surface. The strong adsorption coming from the high average charge transfer value of $1.74 \pm 0.13$ electrons between the adsorbate and the surface ions. In contrast, when DAA adsorbs in the vicinity of the surface $\mathrm{OH}$, as shown in Figure $13 \mathrm{~A}-\mathrm{D}$, the average charge transfer decreases to $1.23 \pm 0.10$ electrons. Taking Figure $13 \mathrm{C}$ as an example, one can see why this is the case. Indeed, although DAA's hydroxyl FG directly interacts with the surface metal ions, the flexible surface proton coordinates with the $\mathrm{O}$ of DAA's carbonyl FG, which physically hinders the direct contact of the carbonyl FG and the surface cations. This weak proton-carbonyl dipole-dipole interaction correlates with the low charge transfer value of 0.91 electrons, a $\sim 2 \AA$ bond length between the carbonyl FG with the surface proton, and DAA's low adsorption energy value of $-1.40 \mathrm{eV}$. Thus, it is the coordination and repellency of the surface proton to the carbonyl FG that are responsible for the reduced average adsorption energy of $2.33 \mathrm{eV}$ and a decreased average electron transfer value of 0.51 electrons. In addition, the surface proton, resulting from dissociation of the water molecule, plays a similar role as the adsorbed surface $\mathrm{OH}$, as shown in Figure S24 and Table S1.

Furthermore, the adsorption configuration of DAA can determine the extent of bond weakening. When DAA is outside of the surface- $\mathrm{OH}$ vicinity, a strong interaction occurs 
between its FGs and surface ions leading to a dramatic deformation of DAA with a severe distortion of the hydroxyl (Figure 13E, F) and the carbonyl (Figure 13H) FGs, stretching the bond distance between the $\mathrm{O}$, from the DAA hydroxyl FG, and the $\mathrm{C}$, from the DAA carbonyl FG, to a $\mathrm{C}-\mathrm{O}$ bond length value of $\sim 3.10 \pm 0.04 \AA$. A smaller $\mathrm{C}-\mathrm{O}$ bond distance of 2.83 A occurs in the configuration shown in Figure 13G, due to the distorted carbon chain. We speculate that dehydration reactions would be more likely to occur on areas of the surface where no surface hydroxyl groups are present. In such a case, our DFT-based model indicates that the $\mathrm{O}-\mathrm{H}$ bond of the DAA hydroxyl FG could dissociate upon its adsorption to the surface, as shown in Figure 13F. $\mathrm{C}-\mathrm{H}$ bond dissociation could also occur from the methyl FG of DAA upon its structural distortion, as the methyl group interacts strongly with the surface (Figure 13G). Significant structural changes have led to a high average distortion energy of $\sim 3.90 \pm 1.09$ $\mathrm{eV}$, which may explain why coking is more likely to occur. These results support the hypothesis that without cofed water, the formed surface DAA is more likely to dehydrate, which eventually leads to surface polymerization/coking (Scheme $4 \mathrm{~B}$ ). In contrast, within the vicinity of the surface OH, DAA's deformation is significantly limited without an apparent distortion of the FGs or the carbon chain, and its integrity is preserved, which hinders further dehydration reactions. This is because the surface $\mathrm{OH}$ inhibits the strong interaction of one of the FGs' with the surface, leading to a much lower distortion energy of $\sim 0.36 \pm 0.01 \mathrm{eV}$. In such a case, the distance between DAA's hydroxyl FG and carbon of the carbonyl group decreases to $\sim 2.90 \pm 0.04 \AA$ (Figure 13A-D). Thus, the surface proton plays a significant role in protecting the integrity of DAA's hydroxyl FG from severe distortion or dehydration reactions, and slightly bends the $\mathrm{O}$ of the hydroxyl FG toward the carbon of the carbonyl FG, which likely makes the formation of the isobutene possible. A summary of these results is given in Figure 14.

\section{CONCLUSIONS}

In this work, we demonstrated that the reaction mechanism of ATIB over a Lewis acid-base pair differs from the widely accepted one proposed on Brønsted acid sites. The distinct roles of water in the ATIB cascade reaction catalyzed by Lewis acid-base pairs (e.g., $\mathrm{Zn}_{x} \mathrm{Z}_{y} \mathrm{O}_{z}$ ) are also extensively elucidated. The reaction follows the acetone-DAA-isobutene mechanism in which DAA decomposition is the r.d.s. (Scheme 5). The rigorous mechanistic interpretation, kinetic evaluations, isotopic study, and DRIFTS-MS analysis confirm that majority of isobutene is directly formed from DAA via an intramolecular reaction with $\mathrm{OH}$ attacking to carbonyl FG of a formed eightmembered ring intermediate. Water is required to competitively adsorb on Lewis acid base pairs, which hinders the formation of $\mathrm{MSO}$ as well as provides an appropriate environment (mobile surface protons) to facilitate the transition from DAA to isobutene.

Our DFT-based model suggests that $\mathrm{OH}$ and $\mathrm{H}$ resulting from the decomposition of adsorbed water on the $\mathrm{Zn}_{x} \mathrm{Z}_{y} \mathrm{O}_{z}$ surface play important roles in protecting DAA from coking because the decomposed $\mathrm{H}$ is predicted to coordinate with the $\mathrm{O}$ of the carbonyl FG, physically hindering the energetic trapping of DAA. Consequently, the adsorbed DAA shows limited distortion when it is adsorbed within the vicinity of the decomposed water. Additionally, the adsorbed $\mathrm{OH}$ tends to repel against the hydroxyl FG, pushing it toward the carbon of the carbonyl FG, which promotes the intramolecular rearrangement of DAA to form isobutene. In contrast, when DAA adsorbs outside of the vicinity of adsorbed water fragment, its adsorption is much stronger, evidenced by the large amount of transferred electrons between the $\mathrm{O}$ of the carbonyl FG, the hydroxyl FG, and the $\mathrm{Zr}^{4+}$ ions of the catalyst surface. The strong interactions between the FGs and the surface result in DAA's dramatic structural distortion, which likely cause subsequent dehydration reactions. Thus, our theoretical calculations demonstrate how the exposure of water to the surface of the catalyst can prevent the energetic trapping of DAA and help facilitate the formation of isobutene.

\section{ASSOCIATED CONTENT \\ Supporting Information}

The Supporting Information is available free of charge at https://pubs.acs.org/doi/10.1021/jacsau.1c00218.

Figure $S 1$, top view of the possible configurations of the dehydrated $\mathrm{Zn}_{1} \mathrm{Zr}_{11} \mathrm{O}_{12}$ surface; Figure S2, relative energy comparisons and top view of the most favorable $\mathrm{Zn}_{1} \mathrm{Zr}_{11} \mathrm{O}_{12}$ surfaces; Figure S3, top view of the possible configurations of a hydrated $\mathrm{Zn}_{1} \mathrm{Zr}_{11} \mathrm{O}_{12}$ surface; Figure S4, relative adsorption energies for the dissociative adsorption of water and top view of the two most favorable configurations on a hydrated $\mathrm{Zn}_{1} \mathrm{Zr}_{11} \mathrm{O}_{12}$ surface; Figure S5: DRIFTS-OH and XRD of fresh and spent $\left(24 \mathrm{~h}\right.$ time on stream, $\mathrm{P}_{\mathrm{H} 2 \mathrm{O}} / \mathrm{P}_{\mathrm{Ace}}=10.7 \mathrm{kPa} / 1$ $\mathrm{kPa}$, space velocity $=0.03$ molAce $/$ gcat $/ \mathrm{h}) \mathrm{Zn}_{1} \mathrm{Zr}_{10} \mathrm{O}_{z}$; Figure S6, DRIFTS of acetone adsorption; Figure S7, conversion and selectivities as a function of time-onstream; Figure S8, acetone conversion and isobutene selectivity as a function of inverse flow rate during steady-state ATIB reaction; Figure S9, ATIB reaction stability over $\mathrm{Zn}_{1} \mathrm{Zr}_{10} \mathrm{O}_{z}$ at different conditions; Figure S10, catalyst evaluation of fresh sample and 10-timeregenerated sample; Figure S11, comparison of acetone to isobutene reaction and acetic acid ketonization; Figure S12, measured $\mathrm{TOF}_{\mathrm{IB}}$; Figure S13, selectivity and conversion; Figure S14, distinct position and corresponding number of each site; Figures S15-18, top views for vertical and horizontal configurations of DAA adsorbed at plausible positions pointing different directions; Figure S19, adsorption energies of possible adsorption sites for the DAA molecule with its FGs pointing away from a dehydrated $\mathrm{Zn}_{1} \mathrm{Z}_{11} \mathrm{O}_{12}$ (1)11) surface and top and side view for the adsorption of DAA at site 10; Figures S20-S23, top view for the horizontal and vertical configurations of DAA adsorbed at plausible positions on Hydrated Surfaces 1 and 2; Figure S24, top and side view of DAA at the sites within the vicinity of the adsorbed $\mathrm{H}$ on Hydrated Surface 2 and at the corresponding sites on the dehydrated $\mathrm{Zn}_{1} \mathrm{Z}_{11} \mathrm{O}_{12}$ surface; Table S1, adsorption energy, distortion energy, and number of transferred electrons for systems in Figure S23; Section S2, derivation of the rate equation for the acetone-DAA-isobutene kinetic model (PDF)

\section{AUTHOR INFORMATION}

Corresponding Authors

Junming Sun - The Gene \& Linda Voiland School of Chemical Engineering and Bioengineering, Washington State University, Pullman, Washington 99164, United States; 
ำ orcid.org/0000-0002-0071-9635; Email: junming.sun@ wsu.edu

Yong Wang - The Gene \& Linda Voiland School of Chemical Engineering and Bioengineering, Washington State University, Pullman, Washington 99164, United States;

Email: yong.wang@pnnl.gov

\section{Authors}

Houqian Li - The Gene \& Linda Voiland School of Chemical Engineering and Bioengineering, Washington State University, Pullman, Washington 99164, United States

Dezhou Guo - The Gene \& Linda Voiland School of Chemical Engineering and Bioengineering, Washington State University, Pullman, Washington 99164, United States

Nisa Ulumuddin - The Gene \& Linda Voiland School of Chemical Engineering and Bioengineering, Washington State University, Pullman, Washington 99164, United States

Nicholas R. Jaegers - The Gene \& Linda Voiland School of Chemical Engineering and Bioengineering, Washington State University, Pullman, Washington 99164, United States; Institute for Integrated Catalysis, Pacific Northwest National Laboratory, Richland, Washington 99352, United States

Bo Peng - Institute for Integrated Catalysis, Pacific Northwest National Laboratory, Richland, Washington 99352, United States

Jean-Sabin McEwen - The Gene \& Linda Voiland School of Chemical Engineering and Bioengineering, Department of Physics and Astronomy, Department of Chemistry, and Department of Biological Systems Engineering, Washington State University, Pullman, Washington 99164, United States; Institute for Integrated Catalysis, Pacific Northwest National Laboratory, Richland, Washington 99352, United States; ○ orcid.org/0000-0003-0931-4869

Jianzhi Hu - Institute for Integrated Catalysis, Pacific Northwest National Laboratory, Richland, Washington 99352, United States; The Gene \& Linda Voiland School of Chemical Engineering and Bioengineering, Washington State University, Pullman, Washington 99164, United States; (1) orcid.org/0000-0001-8879-747X

Complete contact information is available at:

https://pubs.acs.org/10.1021/jacsau.1c00218

\section{Author Contributions}

${ }^{\dagger}$ D.G. and N.U. contributed equally to this work.

\section{Funding}

The work at PNNL was supported by the U.S. Department of Energy, Office of Science, Office of Basic Energy Sciences, Division of Chemical Sciences, Geosciences, and Biosciences' Catalysis Program (FWP-47319). NMR experiments were conducted in the Environmental Molecular Sciences Laboratory (EMSL) (grid.436923.9), a DOE Office of Science User Facility sponsored by the Office of Biological and Environmental Research and located at Pacific Northwest National Laboratory (PNNL). PNNL is a multiprogram national laboratory operated by Battelle for the U.S. Department of Energy under Contract DE-AC05-76RL01830. A portion of the computer time for the computational work was performed using EMSL, a national scientific user facility sponsored by the Department of Energy's Office of Biological and Environmental Research and located at PNNL. This research also used resources of the National Energy Research Scientific Computing Center (NERSC), a U.S. Department of Energy
Office of Science User Facility operated under contract no. DE-AC02-05CH11231. Part of the computational resources were provided by the Kamiak HPC under the Center for Institutional Research Computing at Washington State University.

Notes

The authors declare no competing financial interest.

\section{ACKNOWLEDGMENTS}

The author acknowledges Shandong Chambroad Holding Company for a graduate fellowship.

\section{REFERENCES}

(1) Zhang, M.; Xie, J.; Zhu, C. A general Deoxygenation Approach for Synthesis of Ketones from Aromatic Carboxylic Acids and Alkenes. Nat. Commun. 2018, 9 (1), 1-10.

(2) Zhao, C.; Camaioni, D. M.; Lercher, J. A. Selective Catalytic Hydroalkylation and Deoxygenation of Substituted Phenols to Bicycloalkanes. J. Catal. 2012, 288, 92-103.

(3) Sun, J.; Wang, Y. Recent Advances in Catalytic Conversion of Ethanol to Chemicals. ACS Catal. 2014, 4 (4), 1078-1090.

(4) McAllister, S.; Bailey Jr, W. A.; Bouton, C. The Catalyzed Cleavage of Diacetone Alcohol and Other Ketols and Unsaturated Ketones1. J. Am. Chem. Soc. 1940, 62 (11), 3210-3215.

(5) Herrmann, S.; Iglesia, E. Selective Conversion of Acetone to Isobutene and Acetic Acid on Aluminosilicates: Kinetic Coupling between Acid-Catalyzed and Radical-Mediated Pathways. J. Catal. 2018, 360, 66-80.

(6) Hutchings, G. J.; Johnston, P.; Lee, D. F.; Williams, C. D. Acetone Conversion to Isobutene in High Selectivity using Zeolite $\beta$ Catalyst. Catal. Lett. 1993, 21 (1-2), 49-53.

(7) Li, H.; Sun, J.; Wang, Y. Surface Acetone Reactions on $\mathrm{Zn}_{\mathrm{x}} \mathrm{Zr}_{\mathrm{y}} \mathrm{O}_{\mathrm{z}}$ : A DRIFTS-MS Study. Appl. Catal., A 2019, 573, 22-31.

(8) Sun, J.; Baylon, R. A. L.; Liu, C.; Mei, D.; Martin, K. J.; Venkitasubramanian, P.; Wang, Y. Key Roles of Lewis Acid-Base Pairs on $\mathrm{Zn}_{\mathrm{x}} \mathrm{Zr}_{\mathrm{y}} \mathrm{O}_{\mathrm{z}}$ in Direct Ethanol/Acetone to Isobutene Conversion. J. Am. Chem. Soc. 2016, 138 (2), 507-517.

(9) Tago, T.; Konno, H.; Ikeda, S.; Yamazaki, S.; Ninomiya, W.; Nakasaka, Y.; Masuda, T. Selective Production of Isobutylene from Acetone over Alkali Metal Ion-Exchanged BEA Zeolites. Catal. Today 2011, 164 (1), 158-162.

(10) Dolejšek, Z.; Novakova, J.; Bosáček, V.; Kubelkova, L. Reaction of Ammonia with Surface Species Formed from Acetone on a HZSM5 Zeolite. Zeolites 1991, 11 (3), 244-247.

(11) Xu, T.; Munson, E. J.; Haw, J. F. Toward a Systematic Chemistry of Organic Reactions in Zeolites: In situ NMR Studies of Ketones. J. Am. Chem. Soc. 1994, 116 (5), 1962-1972.

(12) Rorrer, J. E.; Toste, F. D.; Bell, A. T. Mechanism and Kinetics of Isobutene Formation from Ethanol and Acetone over $\mathrm{Zn}_{\mathrm{x}} \mathrm{Zr}_{\mathrm{y}} \mathrm{O}_{\mathrm{z}}$ ACS Catal. 2019, 9, 10588-10604.

(13) Crisci, A. J.; Dou, H.; Prasomsri, T.; Román-Leshkov, Y. Cascade Reactions for the Continuous and Selective Production of Isobutene from Bioderived Acetic Acid Over Zinc-Zirconia Catalysts. ACS Catal. 2014, 4 (11), 4196-4200.

(14) Wang, S.; Goulas, K.; Iglesia, E. Condensation and Esterification Reactions of Alkanals, Alkanones, and Alkanols on $\mathrm{TiO}_{2}$ : Elementary Steps, Site Requirements, and Synergistic Effects of Bifunctional Strategies. J. Catal. 2016, 340, 302-320.

(15) Zaki, M.; Hasan, M.; Pasupulety, L. Surface Reactions of Acetone on $\mathrm{Al}_{2} \mathrm{O}_{3}, \mathrm{TiO}_{2}, \mathrm{ZrO}_{2}$, and $\mathrm{CeO}_{2}:$ IR Spectroscopic Assessment of Impacts of the Surface Acid-Base Properties. Langmuir 2001, 17 (3), 768-774.

(16) Lin, F.; Wang, H.; Zhao, Y.; Fu, J.; Mei, D.; Jaegers, N. R.; Gao, F.; Wang, Y. Elucidation of Active Sites in Aldol Condensation of Acetone over Single-Facet Dominant Anatase $\mathrm{TiO}_{2}(101)$ and (001) Catalysts. JACS Au 2021, 1 (1), 41-52. 
(17) Zaki, M. I.; Hasan, M. A.; Al-Sagheer, F. A.; Pasupulety, L. Surface Chemistry of Acetone on Metal Oxides: IR Observation of Acetone Adsorption and Consequent Surface Reactions on SilicaAlumina versus Silica and Alumina. Langmuir 2000, 16 (2), 430-436.

(18) Boehm, H.-P.; Knözinger, H., Nature and Estimation of Functional Groups on Solid Surfaces. In Catalysis: Science and Technology; Anderson, J. R., Boudart, M., Eds.; Springer: Berlin, 1983; Vol. 4, pp 39-207.

(19) Li, G.; Wang, B.; Resasco, D. E. Water Promotion (or Inhibition) of Condensation Reactions Depends on Exposed Cerium Oxide Catalyst Facets. ACS Catal. 2020, 10, 5373-5382.

(20) Adams, J. S.; Chemburkar, A.; Priyadarshini, P.; Ricciardulli, T.; Lu, Y.; Maliekkal, V.; Sampath, A.; Winikoff, S.; Karim, A. M.; Neurock, M.; Flaherty, D. W. Solvent Molecules form Surface Redox Mediators In Situ and Cocatalyze $\mathrm{O}_{2}$ Reduction on Pd. Science 2021, 371 (6529), 626-632.

(21) Wang, M.; Jaegers, N. R.; Lee, M.-S.; Wan, C.; Hu, J. Z.; Shi, H.; Mei, D.; Burton, S. D.; Camaioni, D. M.; Gutiérrez, O. Y.; et al. Genesis and Stability of Hydronium Ions in Zeolite channels. J. Am. Chem. Soc. 2019, 141 (8), 3444-3455.

(22) Čejka, J.; Jírů, P. Influence of Water on Activity, Selectivity and Deactivation of Zeolites in Acetone Transformation. Collect. Czech. Chem. Commun. 1989, 54 (11), 2998-3002.

(23) Kubelkovå, L.; Ćjka, J.; Novakova, J.; Boszácek, V.; Jirka, I.; Jíaru, P. Acetone Conversion and Deactivation of Zeolites. In Studies in Surface Science and Catalysis; Elsevier, 1989; Vol. 49, pp 12031212 .

(24) Baylon, R. A. L.; Sun, J.; Kovarik, L.; Engelhard, M.; Li, H.; Winkelman, A. D.; Wang, Y. Structural Identification of $\mathrm{Zn}_{\mathrm{x}} \mathrm{Zr}_{\mathrm{y}} \mathrm{O}_{\mathrm{z}}$ Catalysts for Cascade Aldolization and Self-Deoxygenation Reactions. Appl. Catal., B 2018, 234, 337-346.

(25) Li, H.; Sun, J.; Li, G.; Wu, D.; Wang, Y. Real-time Monitoring of Surface Acetone Enolization and Aldolization. Catal. Sci. Technol. 2020, 10 (4), 935-939.

(26) Jaegers, N. R.; Mueller, K. T.; Wang, Y.; Hu, J. Z. Variable Temperature and Pressure Operando MAS NMR for Catalysis Science and Related Materials. Acc. Chem. Res. 2020, 53 (3), 611619.

(27) Jaegers, N. R.; Hu, W.; Wang, Y.; Hu, J. Z., High-Temperature and High-Pressure In situ Magic Angle Spinning Nuclear Magnetic Resonance Spectroscopy. J. Vis. Exp. 2020, (164), DOI: 10.3791/ 61794,

(28) Van Geet, A. L. Calibration of Methanol Nuclear Magnetic Resonance Thermometer at Low Temperature. Anal. Chem. 1970, 42 (6), 679-680.

(29) Sun, J.; Zhu, K.; Gao, F.; Wang, C.; Liu, J.; Peden, C. H.; Wang, $\mathrm{Y}$. Direct Conversion of Bio-Ethanol to Isobutene on Nanosized $\mathrm{Zn}_{\mathrm{x}} \mathrm{Zr}_{\mathrm{y}} \mathrm{O}_{\mathrm{z}}$ Mixed Oxides with Balanced Acid-base Sites. J. Am. Chem. Soc. 2011, 133 (29), 11096-9.

(30) Kresse, G.; Furthmüller, J. Efficient Iterative Schemes for Ab Initio Total-energy Calculations using a Plane-Wave Basis Set. Phys. Rev. B: Condens. Matter Mater. Phys. 1996, 54 (16), 11169.

(31) Kresse, G.; Hafner, J. Ab Initio Molecular Dynamics for Liquid Metals. Phys. Rev. B: Condens. Matter Mater. Phys. 1993, 47 (1), 558.

(32) Kresse, G.; Joubert, D. From Ultrasoft Pseudopotentials to the Projector Augmented-wave Method. Phys. Rev. B: Condens. Matter Mater. Phys. 1999, 59 (3), 1758.

(33) Blöchl, P. E. Projector Augmented-wave Method. Phys. Rev. B: Condens. Matter Mater. Phys. 1994, 50 (24), 17953.

(34) Klimeš, J.; Bowler, D. R.; Michaelides, A. Chemical Accuracy for the Van der Waals Density Functional. J. Phys.: Condens. Matter 2010, 22 (2), 022201.

(35) Momma, K.; Izumi, F. VESTA 3 for Three-dimensional Visualization of Crystal, Volumetric and Morphology Data. J. Appl. Crystallogr. 2011, 44 (6), 1272-1276.

(36) Platt, a.; Frankel, P.; Gass, M.; Howells, R.; Preuss, M. Finite Element Analysis of the Tetragonal to Monoclinic Phase Transformation during Oxidation of Zirconium Alloys. J. Nucl. Mater. 2014, 454 (1-3), 290-297.
(37) Methfessel, M.; Paxton, A. High-precision Sampling for Brillouin-zone Integration in Metals. Phys. Rev. B: Condens. Matter Mater. Phys. 1989, 40 (6), 3616.

(38) McCullough, J. t.; Trueblood, K. The Crystal Structure of Baddeleyite (monoclinic $\mathrm{ZrO}_{2}$ ). Acta Crystallogr. 1959, 12 (7), 507511.

(39) Christensen, A.; Carter, E. A. First-principles Study of the Surfaces of Zirconia. Phys. Rev. B: Condens. Matter Mater. Phys. 1998, 58 (12), 8050.

(40) Piskorz, W.; Grybos, J.; Zasada, F.; Cristol, S.; Paul, J.-F.; Adamski, A.; Sojka, Z. Periodic DFT and Atomistic Thermodynamic Modeling of the Surface Hydration Equilibria and Morphology of Monoclinic $\mathrm{ZrO}_{2}$ Nanocrystals. J. Phys. Chem. C 2011, 115 (49), 24274-24286.

(41) Neugebauer, J.; Scheffler, M. Adsorbate-substrate and Adsorbate-adsorbate Interactions of $\mathrm{Na}$ and $\mathrm{K}$ Adlayers on $\mathrm{Al}(111)$. Phys. Rev. B: Condens. Matter Mater. Phys. 1992, 46 (24), 16067.

(42) Zaki, M. I.; Hasan, M. A.; Al-Sagheer, F. A.; Pasupulety, L. In situ FTIR Spectra of Pyridine Adsorbed on $\mathrm{SiO}_{2}-\mathrm{Al}_{2} \mathrm{O}_{3}, \mathrm{TiO}_{2}, \mathrm{ZrO}_{2}$ and $\mathrm{CeO}_{2}$ : General Considerations for the Identification of Acid Sites on Surfaces of Finely Divided Metal Oxides. Colloids Surf., A 2001, 190 (3), 261-274.

(43) Boehm, H. Acidic and Basic Properties of Hydroxylated Metal Oxide Surfaces. Discuss. Faraday Soc. 1971, 52, 264-275.

(44) Biaglow, A.; Sepa, J.; Gorte, R.; White, D. A ${ }^{13}$ C NMR Study of the Condensation Chemistry of Acetone and Acetaldehyde Adsorbed at the Brønsted Acid Sites in H-ZSM-5. J. Catal. 1995, 151 (2), 373384.

(45) Yi, X.; Ko, H.-H.; Deng, F.; Liu, S.-B.; Zheng, A. Solid-State ${ }^{31} \mathrm{P}$ NMR Mapping of Active Centers and Relevant Spatial Correlations in Solid Acid Catalysts. Nat. Protoc. 2020, 15 (10), 3527-3555.

(46) Zheng, A.; Li, S.; Liu, S.-B.; Deng, F. Acidic properties and structure-activity correlations of solid acid catalysts revealed by solidstate NMR spectroscopy. Acc. Chem. Res. 2016, 49 (4), 655-663.

(47) Mastikhin, V.; Mudrakovsky, I.; Nosov, A. ${ }^{1} \mathrm{H}$ NMR Magic Angle Spinning (MAS) Studies of Heterogeneous Catalysis. Prog. Nucl. Magn. Reson. Spectrosc. 1991, 23 (3), 259-299.

(48) Yang, L.; Feng, N.; Wang, Q.; Chu, Y.; Xu, J.; Deng, F. Surface Water Loading on Titanium Dioxide Modulates Photocatalytic Water Splitting. Cell Rep. Phys. Sci. 2020, 1 (2), 100013.

(49) Li, H.; Pang, J.; Jaegers, N. R.; Kovarik, L.; Engelhard, M.; Savoy, A. W.; Hu, J.; Sun, J.; Wang, Y. Conversion of Ethanol to 1,3butadiene over $\mathrm{Ag}-\mathrm{ZrO}_{2} / \mathrm{SiO}_{2}$ Catalysts: The Role of Surface Interfaces. J. Energy Chem. 2021, 54, 7-15.

(50) Xu, J.; Zheng, A.; Yang, J.; Su, Y.; Wang, J.; Zeng, D.; Zhang, M.; Ye, C.; Deng, F. Acidity of Mesoporous $\mathrm{MoO}_{\mathrm{x}} / \mathrm{ZrO}_{2}$ and $\mathrm{WO}_{\mathrm{x}} /$ $\mathrm{ZrO}_{2}$ Materials: A Combined Solid-State NMR and Theoretical Calculation Study. J. Phys. Chem. B 2006, 110 (22), 10662-10671.

(51) Wang, Z.; Jiang, Y.; Hunger, M.; Baiker, A.; Huang, J. Catalytic Performance of Brønsted and Lewis Acid Sites in Phenylglyoxal Conversion on Flame-Derived Silica-Zirconia. Chem CatChem 2014, 6 (10), 2970-2975.

(52) Schaub, R.; Thostrup, P.; Lopez, N.; Lægsgaard, E.; Stensgaard, I.; Nørskov, J. K.; Besenbacher, F. Oxygen Vacancies as Active Sites for Water Dissociation on Rutile $\mathrm{TiO}_{2}(110)$. Phys. Rev. Lett. 2001, 87 (26), 266104.

(53) Panov, A. G.; Fripiat, J. J. Acetone Condensation Reaction on Acid Catalysts. J. Catal. 1998, 178 (1), 188-197.

(54) Coenen, K.; Gallucci, F.; Mezari, B.; Hensen, E.; van Sint Annaland, M. An in-situ IR Study on the Adsorption of $\mathrm{CO}_{2}$ and $\mathrm{H}_{2} \mathrm{O}$ on Hydrotalcites. J. CO2 Util. 2018, 24, 228-239.

(55) Hilaire, S.; Wang, X.; Luo, T.; Gorte, R.; Wagner, J. A Comparative Study of Water-gas-shift Reaction Over Ceria Supported Metallic Catalysts. Appl. Catal., A 2001, 215 (1-2), 271-278.

(56) Wang, S.; Iglesia, E. Experimental and Theoretical Assessment of the Mechanism and Site Requirements for Ketonization of Carboxylic Acids on Oxides. J. Catal. 2017, 345, 183-206. 
(57) Burch, R. Gold Catalysts for Pure Hydrogen Production in the Water-gas Ahift Reaction: Activity, Structure and Reaction Mechanism. Phys. Chem. Chem. Phys. 2006, 8 (47), 5483-500.

(58) Yang, W.; Geng, Z.; Xu, C.; Guo, Q.; Dai, D.; Yang, X. Controlled Vacancy-Assisted C-C Couplings of Acetaldehyde on Rutile $\mathrm{TiO}_{2}(110)$. J. Phys. Chem. C 2014, 118 (48), 27920-27924.

(59) Calaza, F. C.; Xu, Y.; Mullins, D. R.; Overbury, S. H. Oxygen Vacancy-Assisted Coupling and Enolization of Acetaldehyde on $\mathrm{CeO}_{2}(111)$. J. Am. Chem. Soc. 2012, 134 (43), 18034-45.

(60) Zhao, Y.; Shi, T.; Shang, J.; Ding, L.; Cao, X.; Chen, C.; Zhao, J. Rapid Proton Exchange between Surface Bridging Hydroxyls and Adsorbed Molecules on $\mathrm{TiO}_{2}$. Appl. Catal., B 2020, 277, 119234.

(61) Wang, S.; Iglesia, E. Substituent Effects and Molecular Descriptors of Reactivity in Condensation and Esterification Reactions of Oxygenates on Acid-Base Pairs at $\mathrm{TiO}_{2}$ and $\mathrm{ZrO}_{2}$ Surfaces. J. Phys. Chem. C 2016, 120 (38), 21589-21616.

(62) Simons, M. C.; Vitillo, J. G.; Babucci, M.; Hoffman, A. S.; Boubnov, A.; Beauvais, M. L.; Chen, Z.; Cramer, C. J.; Chapman, K. W.; Bare, S. R.; et al. Structure, Dynamics, and Reactivity for Light Alkane Oxidation of Fe (II) Sites Situated in the Nodes of a MetalOrganic Framework. J. Am. Chem. Soc. 2019, 141 (45), 18142-18151.

(63) Noei, H.; Qiu, H.; Wang, Y.; Löffler, E.; Wöll, C.; Muhler, M. The Identification of Hydroxyl Groups on $\mathrm{ZnO}$ Nanoparticles by Infrared Spectroscopy. Phys. Chem. Chem. Phys. 2008, 10 (47), 70927097.

(64) Zhang, H.; Sun, J.; Liu, C.; Wang, Y. Distinct Water Activation on Polar/non-polar Facets of ZnO Nanoparticles. J. Catal. 2015, 331, $57-62$.

(65) Bartholomew, C. H. Mechanisms of Catalyst Deactivation. Appl. Catal., A 2001, 212 (1-2), 17-60.

(66) Henderson, M. A. Acetone and Water on $\mathrm{TiO}_{2}(110)$ : Competition for Sites. Langmuir 2005, 21 (8), 3443-3450.

(67) Panov, A.; Fripiat, J. Poisoning of Aldol Condensation Reaction with $\mathrm{H}_{2} \mathrm{O}$ on Acid Catalysts. Catal. Lett. 1999, 57 (1-2), 25-32. 